\title{
Connexin32 Mutations Associated with X-Linked Charcot-Marie- Tooth Disease Show Two Distinct Behaviors: Loss of Function and Altered Gating Properties
}

\author{
Catherine Ressot, ${ }^{1,2}$ Danielle Gomès, ${ }^{1}$ André Dautigny, ${ }^{2}$ Danielle Pham-Dinh, ${ }^{2}$ and Roberto Bruzzone ${ }^{1}$ \\ 1 Unité de Neurovirologie et Régénération du Système Nerveux, Institut Pasteur, F-75724 Paris Cedex 15, France, and \\ ¿Laboratoire de Neurogénétique Moléculaire, Unité de Recherche Associée 1488, Centre National de la Recherche \\ Scientifique, Institut des Neurosciences, Université de Paris VI, F-75252 Paris Cedex 05, France
}

The X-linked form of Charcot-Marie-Tooth disease (CMTX) is associated with mutations in the gene encoding connexin32 (Cx32), which is expressed in Schwann cells. We have compared the functional properties of $11 \mathrm{Cx} 32$ mutations with those of the wild-type protein by testing their ability to form intercellular channels in the paired oocyte expression system. Although seven mutations were functionally incompetent, four others were able to generate intercellular currents of the same order of magnitude as those induced by wild-type Cx32 (Cx32wt). In homotypic oocyte pairs, CMTX mutations retaining functional activity induced the development of junctional currents that exhibited changes in the sensitivity and kinetics of voltage dependence with respect to that of $\mathrm{Cx} 32 \mathrm{wt}$. The four mutations were also capable of interacting in heterotypic configuration with the wild-type protein, and in one case the result was a marked rectification of junctional currents in response to volt- age steps of opposite polarity. In addition, the functional CMTX mutations displayed the same selective pattern of compatibility as $\mathrm{Cx} 32$ wt, interacting with $\mathrm{Cx} 26, \mathrm{Cx} 46$, and $\mathrm{Cx} 50$ but failing to do so with $\mathrm{Cx} 40$. Although the functional mutations exhibited sensitivity to cytoplasmic acidification, which induced a $\geq 80 \%$ decrease in junctional currents, both the rate and extent of channel closure were enhanced markedly for two of them. Together, these results indicate that the functional consequences of CMTX mutations of Cx32 are of two drastically distinct kinds. The presence of a functional group of mutations suggests that a selective deficit of $\mathrm{C} \times 32$ channels may be sufficient to impair the homeostasis of Schwann cells and lead to the development of CMTX.

Key words: gap junction; channel; myelin; Schwann cell; neuropathy; peripheral nervous system
Connexins comprise a multigene family of proteins that form the intercellular channels clustered at gap junctions, thereby allowing adjacent cells to share ions, small metabolites, and second messengers (Goodenough et al., 1996; Gros and Jongsma, 1996; Kumar and Gilula, 1996; Yamasaki and Naus, 1996; Bruzzone and Ressot, 1997). Intercellular channels span the plasma membranes of two neighboring cells and result from the association of two half-channels, or connexons, contributed separately by each of the two participating cells. Each connexon, in turn, is a hexameric assembly of connexin subunits (for review, see Sosinsky, 1996; Yeager and Nicholson, 1996). The specific role of connexins in different tissues has been highlighted by the demonstration that two genetic disorders are linked to mutations of connexin genes. Thus, connexin26 (Cx26) mutations are found in hereditary nonsyndromic deafness (Denoyelle et al., 1997; Kelsell et al., 1997;

Received Nov. 17, 1997; revised March 18, 1998; accepted March 20, 1998.

This work was supported by grants from Institut Pasteur and Association Française contre les Myopathies (to R.B); European Leukodystrophies Association (to A.D. and D.P-D.); European Community BIOMED 2, ACCV n.4, and Centre National de la Recherche Scientifique (to A.D.); and a predoctoral fellowship from European Leukodystrophies Association (to C.R.). We thank Christian Giaume, Piotr Bregestovski, and members of the Bruzzone and Dubois-Dalcq labs for their helpful comments on this manuscript and Wilfrid Bergeret for preparing one construct. We give special thanks to David Paul for continuous encouragement and the generous gift of the M12.13 antibody, to Henri Korn for making his lab space available to house our frogs, and to Daniel Eugène and Daniel Brusciano for help in setting up the data acquisition system and introducing us to pCLAMP software.

Correspondence should be addressed to Dr. Roberto Bruzzone, Unité de Neurovirologie et Régénération du Système Nerveux, Institut Pasteur, 25 Rue du Docteur Roux, F-75724 Paris Cedex 15, France.

Copyright (C) 1998 Society for Neuroscience $\quad 0270-6474 / 98 / 184063-13 \$ 05.00 / 0$
Zelante et al., 1997), whereas patients with the X-linked form of Charcot-Marie-Tooth disease (CMTX) have mutations in the gene encoding Cx32 (Bergoffen et al., 1993).

Charcot-Marie-Tooth disease, the most common genetic disorder of the peripheral nervous system, is characterized by distal muscle weakness and amyotrophy, decreased or absent tendon reflexes, and pes cavus deformity (Vance, 1991; Harding, 1995; Suter and Snipes, 1995). In keeping with the proposed role as a candidate gene for CMTX, Cx32 is expressed at high levels in myelinating Schwann cells and is regulated in parallel to other myelin genes (Bergoffen et al., 1993; Scherer et al., 1995; Chandross et al., 1996b; Satake et al., 1997). Immunocytochemical studies have indicated that $\mathrm{Cx} 32$ is localized mainly in noncompacted domains of myelin, such as paranodal loops and SchmidtLanterman incisures (Bergoffen et al., 1993; Miyazaki et al., 1995; Scherer et al., 1995; Spray and Dermietzel, 1995; Chandross et al., 1996b; Nelles et al., 1996). This distribution is incompatible with the formation of orthodox intercellular channels between adjacent cells but, instead, has led to the hypothesis that $\mathrm{Cx} 32$ forms reflexive intracellular channels and provides a radial pathway traversing the myelin sheath and connecting the main body to the adaxonal portion of Schwann cells (Bergoffen et al., 1993; Paul, 1995; Bone et al., 1997).

The initial analysis of CMTX mutations has demonstrated that some interfere with the channel-forming ability of Cx32 (Bruzzone et al., 1994b; Omori et al., 1996), thus suggesting that loss-of-function of Cx32 in Schwann cells and blockade of the pathway it provides across the myelin turns represent the molec- 
ular basis of the disease. This hypothesis has been strengthened by the demonstration that mice lacking Cx32 develop a late-onset peripheral neuropathy with features similar to those of CMTX (Anzini et al., 1997). One CMTX mutation, however, appears to retain functional activity (Rabadan-Diehl et al., 1994; Omori et al., 1996), although its biophysical properties and gating behavior have not been analyzed.

As a first step toward a better understanding of the role of $\mathrm{C} \times 32$ in the pathogenesis of CMTX, we have studied the functional consequences of 11 mutations of $\mathrm{Cx} 32$ found in CMTX patients by testing their ability to form intercellular channels in the paired Xenopus oocytes expression system. Our results indicate that CMTX mutations of Cx32 display drastically distinct functional consequences. Although seven mutations lacked channel activity, four others were able to generate intercellular currents of the same order of magnitude as those induced by wild-type $\mathrm{C} \times 32$ (Cx32wt). These functional CMTX mutations showed altered gating properties, thus suggesting that a more subtle functional deficit may underlie the development of a similar clinical phenotype.

\section{MATERIALS AND METHODS}

Molecular cloning, in vitro transcription, and translation of Cx32wt and CMTX mutations. Human Cx32wt had been subcloned previously (Bruzzone et al., 1994b) into the transcription vector SP64T (Krieg and Melton, 1984). We have analyzed 11 mutations distributed throughout the connexin molecule (see Fig. 1): R22G, R22P (Ressot et al., 1996), L56F, L90H (Latour et al., 1997), V95M (Bone et al., 1995), E102G (Ionasescu et al., 1994), Deletion (Del) 111-116 (Cherryson et al., 1994), P172S (Bergoffen et al., 1993), E208K (Fairweather et al., 1994), Y211stop (Tan et al., 1996), and R220stop (Fairweather et al., 1994; Ionasescu et al., 1994). The following mutations-R22G, R22P, and $\mathrm{L} 90 \mathrm{H}$-were produced by PCR amplification of the coding region of Cx32, using $100 \mathrm{ng}$ of genomic DNA isolated from affected CMTX patients as the template. The two primers corresponded to nucleotides 1-24 (sense, 5'-GTACAGATCTATGAACTGGACAGGTTTGTACACC-3') and 832-849 (antisense, 5'-AATTAGATCTTCAGCAGGCCGAGCAGCGGTC- $\left.3^{\prime}\right)$ of the human $\mathrm{Cx} 32$ coding region $(\mathrm{Ku}-$ mar and Gilula, 1986), with BglII linkers. The cycling protocol and the rest of the cloning procedure were performed as described (Bruzzone et al., 1994b). All other mutations were generated by oligonucleotidedirected site mutagenesis (Ausubel et al., 1992). Briefly, two oligonucleotides that corresponded to adjacent regions of $\mathrm{Cx} 32$, spanning the site to be mutagenized, were synthesized for each CMTX mutation. The appropriately modified codons were contained in the sense primers. Cx32wt, subcloned in the SP64T vector, was used as the template (5-10 $\mathrm{ng})$ and amplified with $P f u$ polymerase $(2.5 \mathrm{U}$; Boehringer Mannheim Biochemicals, Meylan, France), using a previously described protocol (White et al., 1994).

The sequences of PCR primers are given below; codons with altered nucleotides and those flanking the $18 \mathrm{bp}$ deletion are underlined. L56F, sense, 5'-TGC-AAC-ACA-TTC-CAG-CCT-GGC-3'; L56F, antisense, 5'GAT-GAA-GGA-AGA-TTT-CTC-ATC-3'; V95M, sense, 5'-GCC-ATGCAC-ATG-GCT-CAC-CAG-3'; V95M, antisense, 5'-CAC-GAG-GAGAGC-TGG-GGT-GGA-3'; E102G, sense, 5'-CAA-CAC-ATA-GGGAAG-AAA-ATG-3'; E102G, antisense, 5'-CTG-GTG-AGC-CAC-GTGCAT-GGC-3'; Del111-116, sense, 5'-CTG-GAG-GAG-GTG-AAG-AGGCAC-3'; Del111-116, antisense, 5'-GCC-CTC-AAG-CCG-TAG-CATTTT-3'; P172S, sense, 5'-GAC-GTC-TAC-TCC-TGC-CCC-3'; P172S, antisense, $5^{\prime}$-GCA-CTT-GAC-CAG-CCG-CAC-3'; E208K, sense, 5'-AATGTG-GCC-AAG-GTG-GTG-TAC-3'; E208K, antisense, 5'-GAG-GATGAT-GCA-GAT-GCC-AGA-3'; Y211stop, sense, 5'-GAG-GTG-GTGTAA-CTC-ATC-ATC-3'; Y211stop, antisense, 5'-GGC-CAC-ATT-GAGGAT-GAT-GCA-3'; R220stop, sense, 5'-TGT-GCC-CGC-TGA-GCCCAG-CGC-3'; and R220stop, antisense, 5'-GGC-CCG-GAT-GAT-GAGGTA-CAC-3'.

To verify that the CMTX mutations had been incorporated and to ensure that PCR amplification did not introduce random errors in the $\mathrm{Cx} 32$ coding sequence, we sequenced all constructs entirely with Sequenase (Amersham, Buckinghamshire, UK), following the protocols recommended by the manufacturer. Constructs were linearized with $X b a \mathrm{I}$, and capped cRNAs were produced in vitro with SP6 RNA polymerase, using the mMessage mMachine kit (Ambion, Austin, TX) according to the manufacturer's instructions. The purity and yield of transcribed cRNAs were determined either by comparison of the intensity of ethidium bromide staining to a known RNA standard ladder after agarose gel electrophoresis or by measuring absorbance at $260 \mathrm{~nm}$. Aliquots $(300-$ $500 \mathrm{ng}$ ) of in vitro synthesized connexin cRNAs were translated (1 hr at $37^{\circ} \mathrm{C}$ ) in a rabbit reticulocyte lysate system (New England Nuclear, Boston, MA), following previously described protocols (Bruzzone et al., 1994a). Radioactive products ( $1 / 10$ of the reaction volume) were separated by electrophoresis on a $13 \%$ SDS-polyacrylamide gel and visualized by fluorography.

Preparation of Xenopus oocytes. Ovarian lobes were removed surgically under cold anesthesia from Xenopus laevis females purchased from the colony of the Institut für Entwicklungsbiologie (Hamburg, Germany). Oocytes (stage V-VI) were defolliculated after collagenase treatment and processed for the paired oocyte expression assay as previously described (Dahl, 1992). After collagenase digestion and defolliculation, all subsequent steps were performed at $18^{\circ} \mathrm{C}$ in modified Barth's (MB) medium as previously described (Swenson et al., 1989), except in experiments using $\mathrm{Cx} 46$, in which the final concentration of calcium was adjusted to $2.9 \mathrm{~mm}$ with $\mathrm{CaCl}_{2}$ (Ebihara and Steiner, 1993). To eliminate the possible contribution of endogenous intercellular channels to the measured conductance (Barrio et al., 1991; Bruzzone et al., 1993), we injected the oocytes with an antisense oligonucleotide (3 ng/oocyte) corresponding to a portion of the coding sequence of Xenopus Cx38 mRNA (5'-CTGACTGCTCGTCTGTCCACACAG-3'). After an overnight incubation at $18^{\circ} \mathrm{C}$, each antisense-treated oocyte was injected with $40 \mathrm{nl}$ of either water or appropriate dilutions of the various cRNAs. Microinjected oocytes were immersed for a few minutes in hypertonic solution to strip the vitelline envelope (Methfessel et al., 1986), transferred to Petri dishes containing MB medium, and manually paired with the vegetal poles apposed.

Labeling of connexin proteins and Western blotting. Metabolic labeling of oocytes was performed as previously described (Bruzzone et al., 1993), except that each cell received $2 \mu \mathrm{Ci}$ of L- $\left[{ }^{35} \mathrm{~S}\right] \mathrm{methionine} \mathrm{(ICN} \mathrm{Phar-}$ maceuticals, Costa Mesa, CA) together with water or cRNA (120-200 $\mathrm{ng})$. Approximately $1 / 2$ of one oocyte was loaded onto each lane of a $13 \%$ SDS-polyacrylamide gel; after migration, labeled proteins were visualized by fluorography. For Western blotting, oocytes injected in parallel with the same cRNA aliquots used for electrophysiological experiments were transferred to chilled Eppendorf tubes containing lysis buffer [(in mM) 5 Tris, 5 EDTA, and 5 EGTA, pH 8.0, plus $10 \mu \mathrm{g}$ each of chymostatin, leupeptin, and pepstatin] and homogenized to prepare a crude membrane fraction, as previously described (White et al., 1994). For each experimental condition two oocyte equivalents per lane were loaded on a $13 \%$ SDS-polyacrylamide gel. After separation, proteins were transferred $(1 \mathrm{hr}$ at $50 \mathrm{~V})$ to nitrocellulose membranes (Schleicher \& Schuell, Keene, $\mathrm{NH})$ at $4^{\circ} \mathrm{C}$ with precooled buffer $(1.92 \mathrm{M}$ glycine, 248 mu Tris-base, and 20\% methanol). Transferred proteins were visualized by staining the membranes with $0.2 \%(w / v)$ Ponceau S, and the position of molecular weight standards was marked with a needle. All subsequent steps were performed at room temperature, using the reagents provided with the Western-Light kit (Tropix, Bedford, MA) according to the manufacturer's recommendations. The culture supernatant of an antiCx32 monoclonal antibody, designated as M12.13 (Goodenough et al., 1988), was used at a 1:50 dilution. After three washes, the membranes were reacted for $30 \mathrm{~min}$ with an alkaline phosphatase-conjugated goat anti-mouse IgG plus IgM (H+L) (Tropix) used at a final dilution of 1:2500, and the protein bands were visualized by chemiluminescence.

Electrophysiological measurements of junctional currents. Intercellular communication was quantitated by double voltage clamp (Spray et al., 1981) $24-48 \mathrm{hr}$ after pairing. Electrodes had a resistance of $0.5-2 \mathrm{M} \Omega$ and were filled with (in $\mathrm{M}) 3 \mathrm{KCl}, 10$ EGTA, and $10 \mathrm{HEPES}, \mathrm{pH} 7.4$. Voltage clamping of oocyte pairs was performed with two GeneClamp 500 amplifiers (Axon Instruments, Foster City, CA) controlled by a PC-compatible computer (Kenitec, Taiwan) via a Digidata 1200 interface (Axon Instruments). pCLAMP 6.0 software (Axon Instruments) was used to program stimulus and data collection paradigms. Current outputs were filtered at $10 \mathrm{~Hz}$, and the sampling interval was $7.5 \mathrm{msec}$. For simple measurements of junctional conductance, both cells of a pair were clamped initially at $-40 \mathrm{mV}$ to ensure zero transjunctional potential, and alternating pulses of $\pm 10-20 \mathrm{mV}$ were imposed to one cell. Current delivered to the cell clamped at $-40 \mathrm{mV}$ during the voltage pulse was equal in magnitude to the junctional current and was divided 


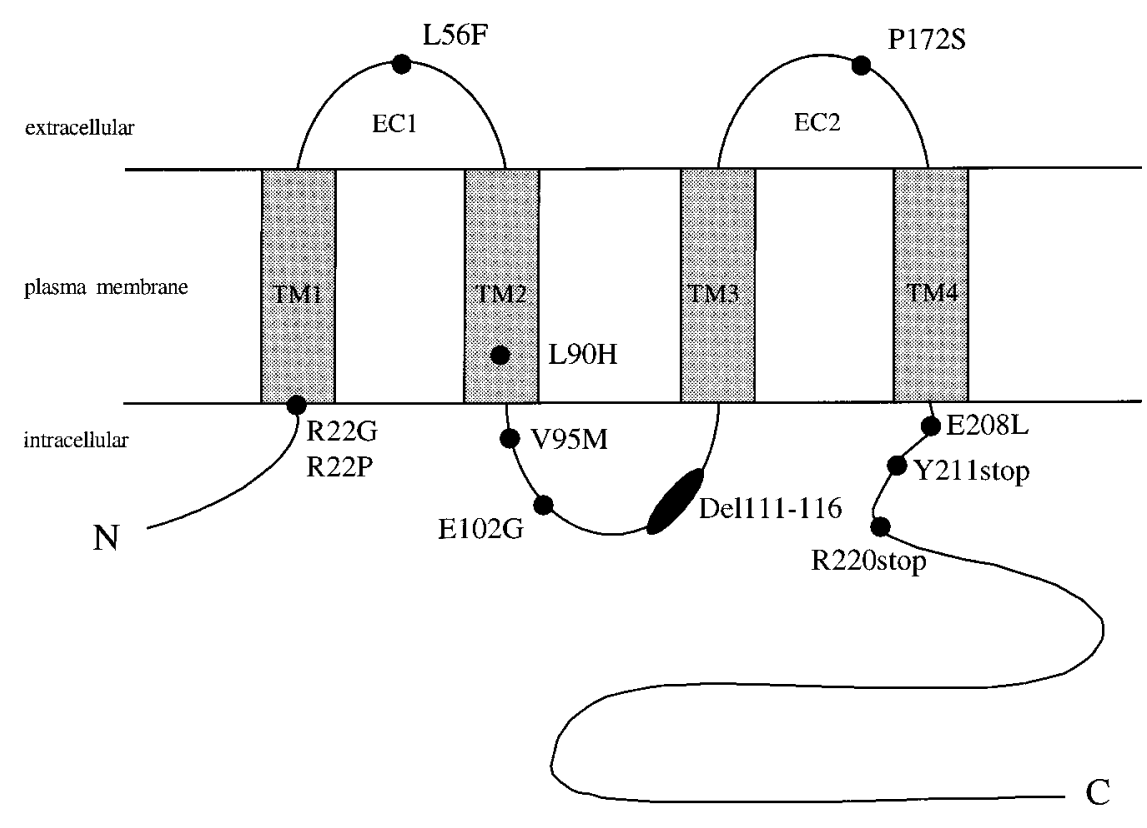

Figure 1. Schematic representation and topology relative to the plasma membrane of $\mathrm{Cx} 32$, with the approximate location of the CMTX mutations analyzed: two were in the first transmembrane domain (TM1), one in the first extracellular loop (EC1), one in the second transmembrane domain (TM2), three in the middle cytoplasmic region, one in the second extracellular loop (EC2), and three in the C-terminal portion $(C)$. by the voltage to yield the conductance. Transjunctional potentials of increasing amplitude and opposite polarity were generated by hyperpolarizing or depolarizing one cell in $10 \mathrm{mV}$ increments while clamping the second cell at $-40 \mathrm{mV}$; steady-state currents were measured $30 \mathrm{sec}$ after the imposition of voltage steps. Then the calculated conductance was normalized to its value at $\pm 10 \mathrm{mV}$ and plotted against the transjunctional potential. Data were fit to a Boltzmann equation of the form: $G_{\text {iss }}$ $=\left(G_{\text {jmax }}-G_{\text {jmin }}\right) /\left\{1+\exp \left(A\left[V-V_{0}\right]\right)\right\}+G_{\text {jmin }}$, where $G_{\text {jss }}$ is the steady-state conductance, $G_{\text {jmax }}$ is maximum conductance, $G_{\text {jmin }}$ is minimum conductance, $A$ is the cooperativity constant, and $V_{0}$ is the voltage at which the decrease in $G_{\text {jss }}$ is half-maximal (Spray et al., 1981). The mean conductance of oocyte pairs selected for analysis of voltage sensitivity was $4.5 \pm 0.4 \mu \mathrm{S}(n=49)$, thereby ensuring adequate control of transjunctional potential and avoiding the risk of overestimating the actual $G_{\mathrm{j}}$ at steady state (Wilders and Jongsma, 1992). The kinetics of voltage-dependent transitions of junctional conductance were fit with Clampfit functions in pCLAMP (Axon Instruments), using the following equation: $A n \times \exp \{-(t-K) / \tau n\}+C$, where $\tau$ is the time constant reported for each component $(n), K$ is the time at the start of the fit region, $A$ is the current amplitude evaluated at the time $t=K$, and $C$ is the steady-state asymptote. Experimental time constants $(\tau)$ were calculated for transjunctional voltages $\geq 50 \mathrm{mV}$, which corresponded to values resulting in a consistent voltage-dependent closure of channels composed of either Cx32wt or functional CMTX mutations. The sensitivity of junctional conductance to cytoplasmic acidification was tested by perfusing the incubation dish $(4.2 \mathrm{ml} / \mathrm{min}$; total dish volume, $5 \mathrm{ml})$ with $\mathrm{MB}$ medium equilibrated with $100 \% \mathrm{CO}_{2}$ for $10 \mathrm{~min}$, after which the perfusion medium was switched to normal $\mathrm{MB}$ to allow junctional conductance to recover. Junctional conductance was measured in response to alternating $\pm 10 \mathrm{mV}$ pulses applied, for $1 \mathrm{sec}$ at $1 \mathrm{~min}$ intervals, to one cell and normalized to the average conductance values recorded for 3 min previous to the start of perfusion with $100 \% \mathrm{CO}_{2}$.

Statistical analysis. Results are shown as the mean \pm SEM. Two population comparisons were made with Student's unpaired $t$ test; $p$ values of 0.05 or less were considered to be significant.

\section{RESULTS}

\section{Biochemical characterization and expression of CMTX mutations in Xenopus oocytes}

The CMTX mutations and their approximate localization on Cx32 are illustrated in Figure 1. The constructs were used as templates for in vitro transcription and the subsequent translation of the produced cRNAs, using a rabbit reticulocyte lysate in the presence of $\mathrm{L}_{-}\left[{ }^{35} \mathrm{~S}\right]$ methionine. The radioactive products were separated by SDS-gel electrophoresis and detected by fluorography (Fig. 2A). Translation reactions that contained cRNAs en- coding a CMTX missense mutation (Fig. 2A, lanes 2-7, 9, 10) produced a predominant band of the same apparent size as that of the wild-type $\mathrm{Cx} 32$ protein (Fig. $2 A$, lane 1 ). The deletion of six amino acids at residues 111-116 (Fig. 2A, lane 8) did not change appreciably the migration of the construct under the experimental conditions that were used. As expected, translation reactions that contained cRNAs for either Y211stop or R220stop (Fig. 2A, lanes 11-12, respectively), the two mutations resulting in premature stop codons, produced proteins migrating with a faster electrophoretic mobility that was in agreement with their predicted molecular mass.

We next verified the translation efficacy of the CMTX constructs in Xenopus oocytes by Western blotting of membrane fractions (Fig. 2B). The monoclonal antibody M12.13 (Goodenough et al., 1988) identified a major polypeptide band of $\sim 27$ $\mathrm{kDa}$ in oocytes injected with cRNAs encoding either Cx32wt or CMTX mutations, except in the case of cells receiving Del111116, for which no bands were recognized by the antibody (Fig. $2 B$, lane 8 ). This failure could have been attributable either to a very rapid degradation of the synthesized protein in a cellular environment or to the disruption of the epitope recognized by M12.13, which is known to be exposed on the cytoplasmic side (Goodenough et al., 1988). To distinguish between this alternative, we metabolically labeled oocyte proteins with $\mathrm{L}-\left[{ }^{35} \mathrm{~S}\right]$ methionine and analyzed aliquots of homogenates for incorporation of label into total protein. Oocytes injected with cRNA for Del111-116 produced high levels of the encoded mutation (Fig. 2C, lane 3) that were comparable to those observed with the injection of a similar amount of cRNA encoding Cx32wt (Fig. 2C, lane 1). Thus, the monoclonal antibody M12.13 recognizes an epitope in the middle cytoplasmic loop of $\mathrm{Cx} 32$ that is destroyed by the deletion of amino acid residues 111-116. In addition, the injection of L90H cRNA induced the synthesis of a specific protein band (Fig. $2 C$, lane 2 ) of the same intensity as that of $\mathrm{Cx} 32 \mathrm{wt}$. This result indicates that the lower immunoreactivity noticed in Western blots (Fig. 2B, lane 5) is not attributable to a reduced translatability of this cRNA but suggests a conformational change that would affect the antibody epitope in the cytoplasmic portion. Because the $\mathrm{L} 90 \mathrm{H}$ mutation occurs in the second 

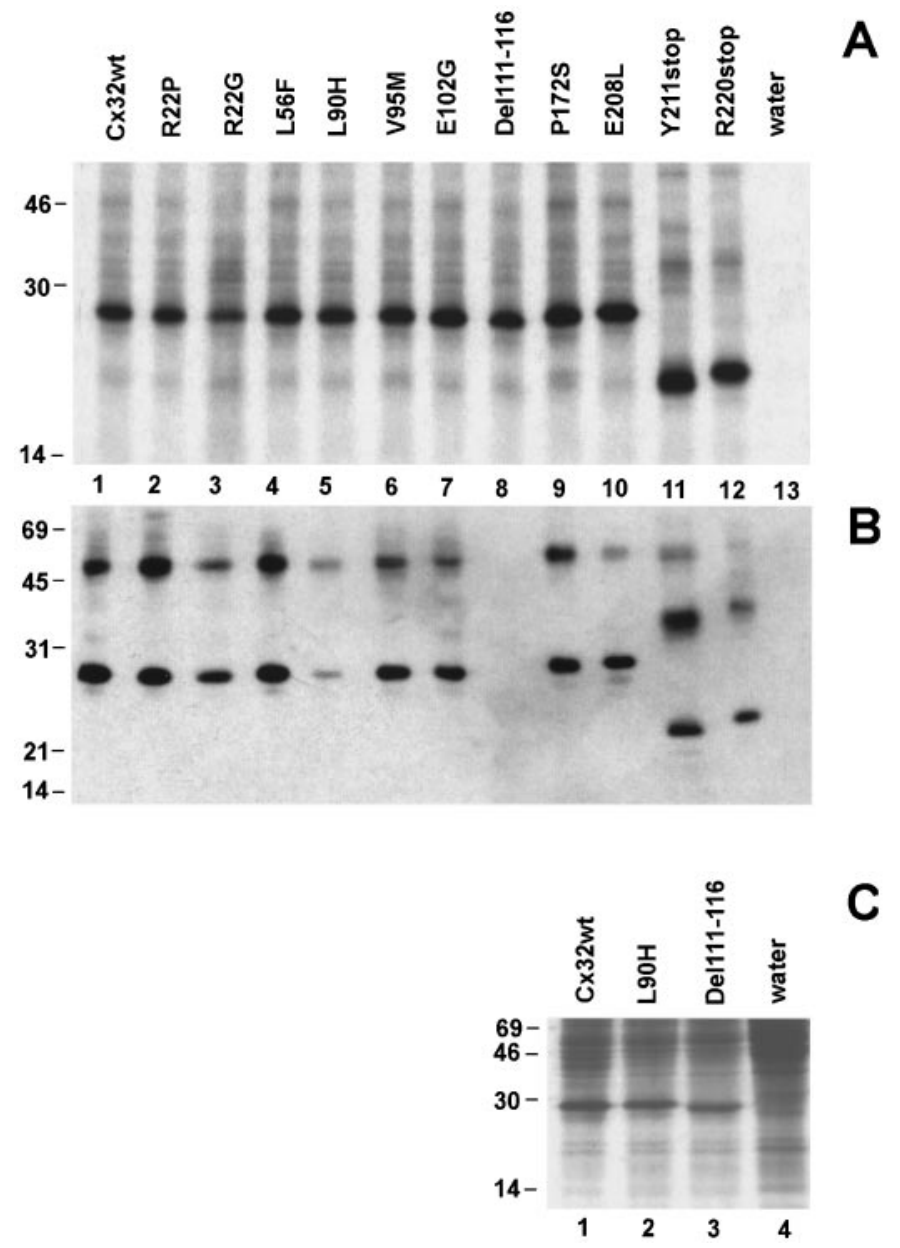

Figure 2. CMTX mutations of Cx32 are expressed by Xenopus oocytes injected with in vitro transcribed cRNAs. $A$, In vitro translation of cRNAs of Cx32wt and CMTX mutations. Each cRNA directed the synthesis of a major polypeptide product that, in the case of the two mutations predicting a premature stop codon, migrated with the expected faster electrophoretic mobility. B, Western blots of Xenopus oocytes membranes. In oocytes that received cRNAs for either wild type or 10 of 11 CMTX mutations of $\mathrm{Cx} 32$, the antibody M12.13 (Goodenough et al., 1988) reacted with a major protein product that exhibited the expected SDS-gel mobility between 22 and $28 \mathrm{kDa}$. In addition, the antibody recognized a protein band with slower electrophoretic mobility, most likely a dimer of $\mathrm{Cx} 32$. No major proteins were detected in control, water-injected oocytes (lane 13), as well as in membranes prepared from oocytes injected with the Del111-116 mutation (lane 8). C, Metabolic labeling of Xenopus oocytes. Oocytes injected with cRNAs produced high levels of the encoded proteins (lanes 1-3), which were easily detected above the background of endogenous proteins synthesized by water-injected cells (lane 4). Experimental conditions are indicated at the top of each lane. The molecular mass (in $\mathrm{kDa}$ ) and migration of protein standards are indicated on the left edge of each gel.

transmembrane segment, this observation is compatible with the idea of interdomain interactions in connexins (Verselis et al., 1994; White and Bruzzone, 1996; Wang and Peracchia, 1997; Zhou et al., 1997). Thus, Xenopus oocytes support the efficient biosynthesis of all CMTX mutations of Cx32.

\section{Functional expression of CMTX mutations}

Intercellular channels are defined as homotypic, when both connexons are composed of the same connexin, or heterotypic, when each connexon contains a different connexin. The ability of CMTX mutations to form homotypic channels was tested by

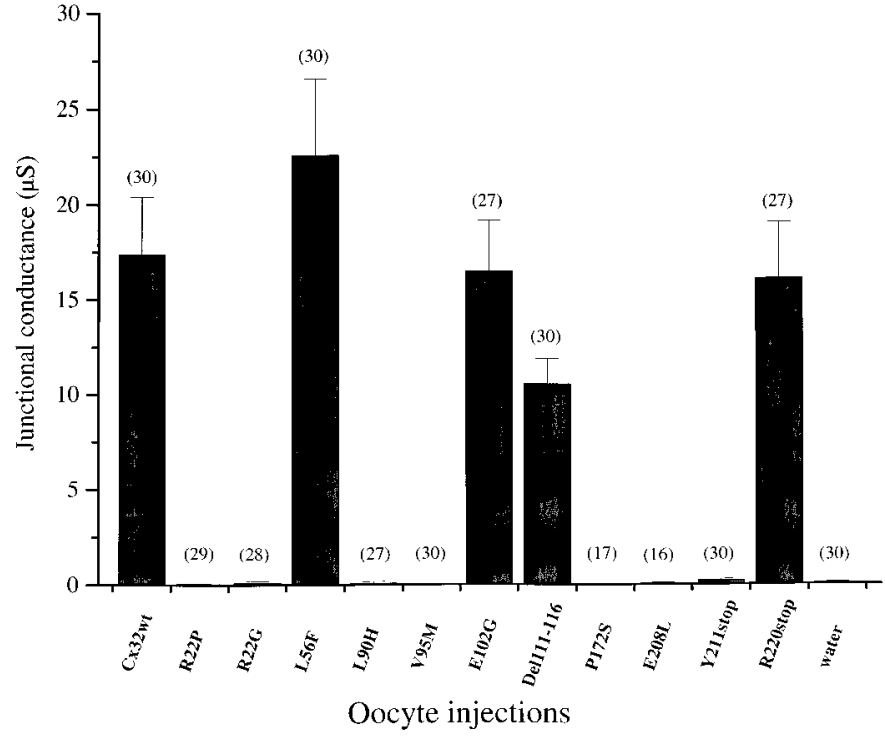

Figure 3. Expression of CMTX mutations of Cx32 in homotypic oocyte pairs reveals two opposite behaviors. Antisense-treated oocytes (see Materials and Methods) were injected with the specified cRNAs and paired in homotypic configuration for $24-48 \mathrm{hr}$ before junctional conductance was measured by a dual voltage-clamp procedure. Four of the CMTX mutations retained channel-forming activity that was macroscopically indistinguishable from that of Cx32wt. Data were pooled from at least three independent experiments and are presented as the mean \pm SEM of the number of pairs indicated for each condition.

using the paired Xenopus oocyte expression system. Although Cx32 is not known to interact with the endogenous Xenopus Cx38 (Swenson et al., 1989; Werner et al., 1989; White et al., 1995), all experiments were performed with oocytes pretreated with antisense oligonucleotides to ensure that the observed currents were the result of the exogenously supplied connexins. As previously reported (Barrio et al., 1991; Bruzzone et al., 1993), waterinjected cells showed no detectable coupling under these conditions (Fig. 3).

Injection of cRNAs for seven (R22G, R22P, L90H, V95M, P172S, E208L, Y211stop) of the 11 mutations that were analyzed did not induce the formation of homotypic junctional channels, because the levels of conductance that were measured never exceeded background values (Fig. 3). In contrast, the following four mutations-L56F, E102G, Del111-116, and R220stop-efficiently assembled homotypic channels and induced conductance levels of the same order of magnitude as those developed by homotypic pairs expressing Cx32wt (Fig. 3).

\section{Homotypic CMTX channels display distinct voltage-gating properties}

Although four CMTX mutations retained the ability to form functional channels, it remained possible that some of their electrical properties and gating behavior were altered. To address this issue, we first examined the response of homotypic L56F, E102G, Del111-116, and R220stop channels to voltage gating (Fig. 4, Table 1). Typical transjunctional currents and plots of the relationship between steady-state junctional conductance $\left(G_{\mathrm{j}}\right)$ and transjunctional voltage $\left(V_{\mathrm{j}}\right)$ are presented in Figure 4. Voltage steps lasted $30 \mathrm{sec}$ to allow currents to approach equilibrium values. The junctional currents of $\mathrm{Cx} 32 \mathrm{wt}$ pairs decayed slowly over time for potentials $>40 \mathrm{mV}$ (Figs. $4 A, 5 A$ ), in agreement with previous studies that used the rodent homologs (Barrio et al., 
A

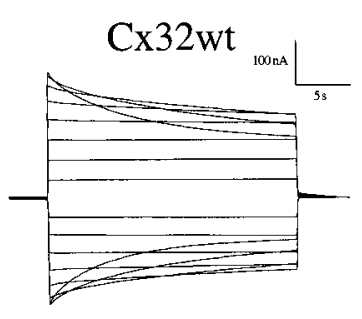

$\mathrm{B}$

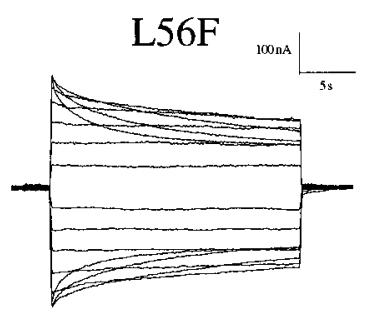

$\mathrm{C}$

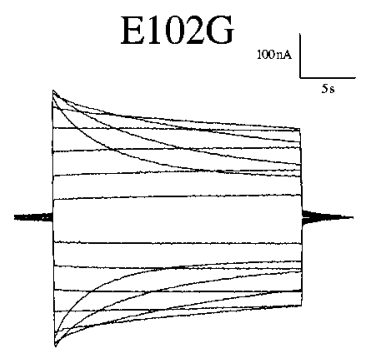

$\mathrm{D}$
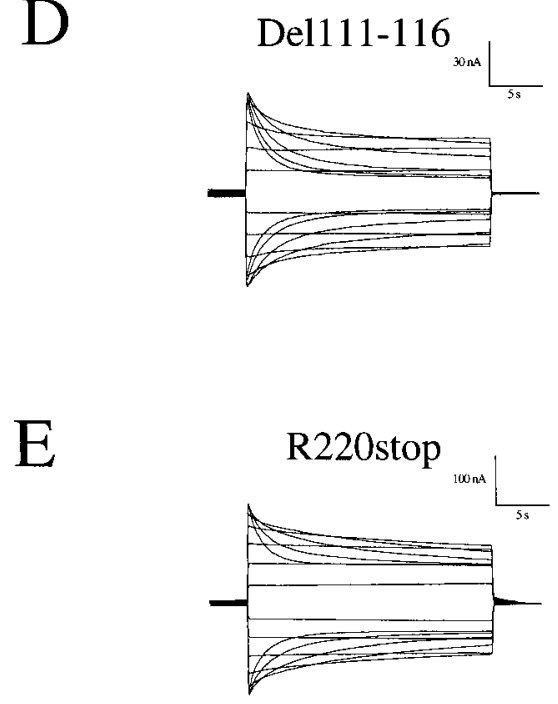
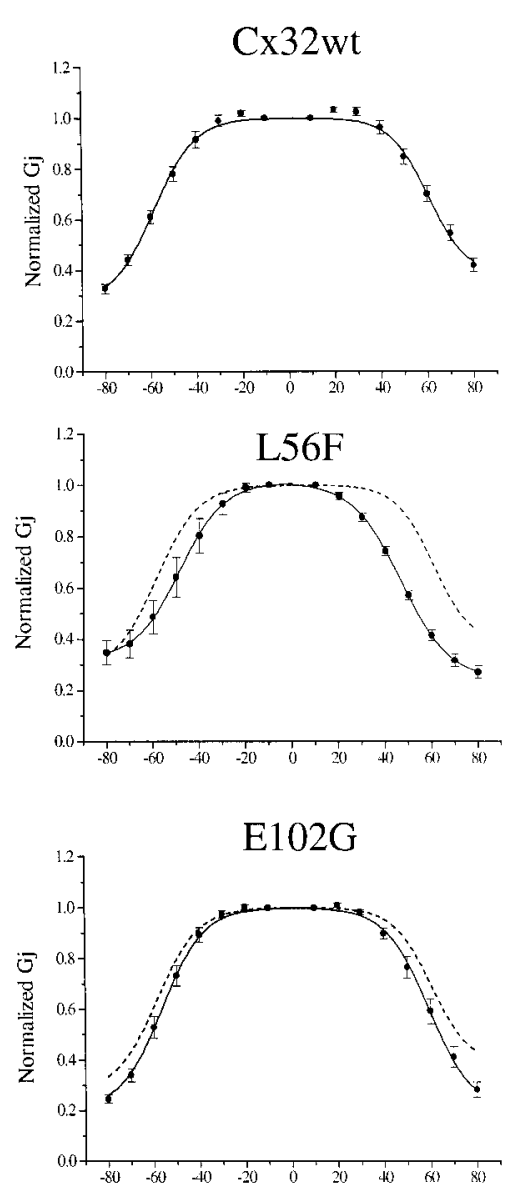

$\mathrm{H}$
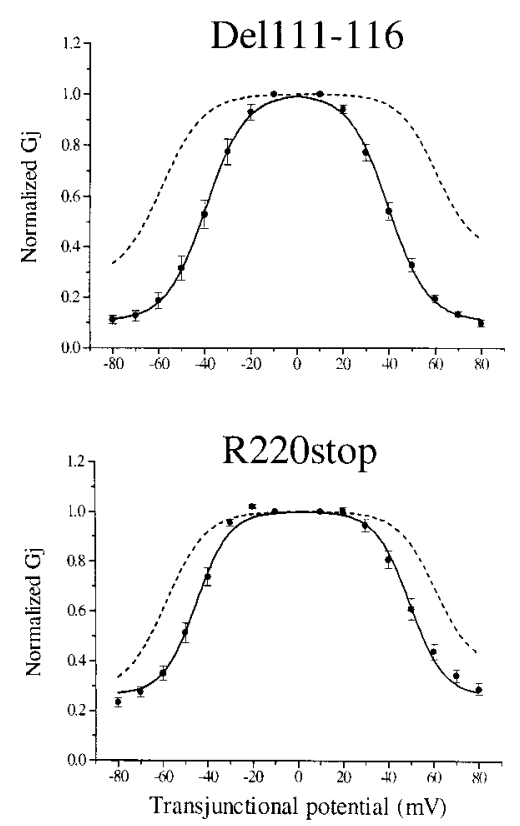

Figure 4. Intercellular channels formed by CMTX mutations of Cx32 exhibit distinct voltage dependence. Antisense-treated oocytes (see Materials and Methods) were injected with the specified cRNAs and then paired homotypically for measurements of junctional currents, using a dual voltage-clamp procedure. $A-E$, Time-dependent decay of junctional currents $\left(I_{\mathrm{j}}\right)$ induced by transjunctional voltage $\left(V_{\mathrm{j}}\right)$ steps of opposite polarity applied in $10 \mathrm{mV}$ increments. Currents from oocytes expressing Cx32wt $(A)$ decayed with a slow time course for $V_{\mathrm{j}} \geq 40 \mathrm{mV}$. CMTX mutations $(B-E)$ showed changes in voltage-induced channel closure that were particularly pronounced in the case of Del111-116 $(D)$. $F-J$, Plots describe the relationship of $V_{\mathrm{j}}$ to steady-state junctional conductance $\left(G_{\mathrm{j}}\right)$, normalized to the values obtained at $\pm 10 \mathrm{mV}$. Smooth lines represent the best fits to Boltzmann equations for which the parameters are given in Table 1 . $G-J$, For the sake of comparison, dashed lines show the Boltzmann curve of Cx32wt. Results are shown as the mean \pm SEM of the following number of oocyte pairs: Cx32wt, $n=7$; L56F, $n=5$; E102G, $n=7$; Del111-116, $n=6$; R220stop, $n=4$. 


\begin{tabular}{|c|c|c|c|c|}
\hline \multirow[t]{2}{*}{$\mathrm{Cx}(\text { condition })^{a}$} & $A$ & $n$ & $V_{0}(\mathrm{mV})$ & $G_{\text {jmin }}$ \\
\hline & \multicolumn{4}{|c|}{ Homotypic } \\
\hline $\mathrm{Cx} 32 \mathrm{wt}\left(+V_{\mathrm{j}}\right)$ & 0.12 & 3.0 & 61 & 0.38 \\
\hline $\mathrm{Cx} 32 \mathrm{wt}\left(-V_{\mathrm{j}}\right)$ & 0.11 & 2.7 & 59 & 0.27 \\
\hline $\mathrm{L} 56 \mathrm{~F}\left(+V_{\mathrm{j}}\right)$ & 0.09 & 2.4 & 47 & 0.24 \\
\hline $\mathrm{L} 56 \mathrm{~F}\left(-V_{\mathrm{j}}\right)$ & 0.11 & 2.7 & 48 & 0.32 \\
\hline E102G & 0.11 & 2.7 & 58 & 0.20 \\
\hline Del111-116 & 0.12 & 3.0 & 40 & 0.11 \\
\hline \multirow[t]{2}{*}{ R220stop } & 0.13 & 3.2 & 47 & 0.26 \\
\hline & \multicolumn{4}{|c|}{ Heterotypic $^{b}$} \\
\hline $\mathrm{L} 56 \mathrm{~F} / \mathrm{C} \times 32 \mathrm{wt}\left(+V_{\mathrm{j}}\right)$ & 0.10 & 2.5 & 62 & 0.24 \\
\hline $\mathrm{L} 56 \mathrm{~F} / \mathrm{C} \times 32 \mathrm{wt}\left(-V_{\mathrm{j}}\right)$ & 0.13 & 3.2 & 52 & 0.23 \\
\hline $\mathrm{E} 102 \mathrm{G} / \mathrm{Cx} 32 \mathrm{wt}\left(+V_{\mathrm{j}}\right)$ & 0.12 & 3.0 & 54 & 0.15 \\
\hline $\mathrm{E} 102 \mathrm{G} / \mathrm{Cx} 32 \mathrm{wt}\left(-V_{\mathrm{j}}\right)$ & 0.12 & 3.0 & 55 & 0.27 \\
\hline Del111-116/Cx32wt $\left(+V_{\mathrm{j}}\right)$ & 0.13 & 3.2 & 37 & 0.10 \\
\hline $\mathrm{R} 220$ stop/Cx32wt $\left(+V_{\mathrm{j}}\right)$ & 0.14 & 3.5 & 43 & 0.25 \\
\hline $\mathrm{R} 220$ stop/Cx32wt $\left(-V_{\mathrm{j}}\right)$ & 0.12 & 3.0 & 54 & 0.27 \\
\hline
\end{tabular}

$\overline{\text { Junctional conductance }\left(G_{\mathrm{j}}\right) \text { developed between pairs of Xenopus oocytes expressing }}$ different constructs was measured by dual voltage clamp in response to increasing transjunctional potentials $\left(V_{\mathrm{j}}\right)$ of opposite polarity, as described in Materials and Methods. The same pairs presented in Figures 4 and 6 were used to calculate the parameters derived from the best fits to the Boltzmann equation given in Materials and Methods. $G_{\text {jmin }}$ is the normalized conductance at the largest $V_{\mathrm{j}}( \pm 80 \mathrm{mV})$, and $V_{0}$ is the voltage at which half-maximal decrease of $G_{\mathrm{j}}$ occurs. The cooperativity constant $A$, a parameter reflecting the slope of the curve, also can be expressed as the gating charge $n$, where $n=A(k T / q)$ with $k=$ Boltzmann constant, $T=$ absolute temperature, and $q=$ elementary charge.

${ }^{a}$ The plus and minus signs for $V_{\mathrm{j}}$ refer to the polarity of the transjunctional potential. When not indicated, the response was symmetrical.

${ }^{b}$ In all cases the cell expressing Cx32wt was either depolarized or hyperpolarized, whereas the other oocyte, expressing the CMTX mutation, was held at a constant voltage. Thus, positive $V_{\mathrm{j}}$ denotes that the wild-type injected oocyte is relatively positive, whereas negative $V_{\mathrm{j}}$ denotes that the cell expressing the CMTX mutation is relatively positive. The voltage-induced channel closure of the Del111-116 side could not be fit by a Boltzmann equation.

1991; Rubin et al., 1992; Suchyna et al., 1993; Bruzzone et al., 1994a; Wang and Peracchia, 1996). Conductance values measured at the end of the imposed pulses were normalized to those recorded at the lower transjunctional potential (i.e., $\pm 10 \mathrm{mV}$ ) and were plotted against the increasing $V_{\mathrm{j}}$ of either polarity. As previously reported (Bruzzone et al., 1994a), the $G_{\mathrm{j}} / V_{\mathrm{j}}$ relationship showed a slight asymmetry, with positive potentials inducing a greater channel closure over the duration of the voltage step (Fig. $4 F$ ). This asymmetry was quantitated by fitting the $G_{\mathrm{j}} / V_{\mathrm{j}}$ relationship for positive and negative polarity to Boltzmann equations, for which the parameters are given in Table 1.

Oocyte pairs expressing channels made by the functional CMTX mutations showed a voltage dependence that appeared to be more pronounced in comparison to that of Cx32wt (Fig. $4 B-E)$. In particular, Del111-116 homotypic pairs exhibited a marked sensitivity to voltage, with junctional currents decaying symmetrically at $V_{\mathrm{j}} \geq 30 \mathrm{mV}$ and a value of transjunctional potential at which the transition between maximal and minimal conductance was halfway $\left(V_{0}\right)$ of $40 \mathrm{mV}$ (Fig. 4D, Table 1). Finally, the extent of channel closure was more complete, as reflected in the value of minimal conductance $\left(G_{\text {jmin }}\right)$, which was only $10 \%$ of the maximal level measured at the lowest $V_{\mathrm{j}}$ (Fig. $4 I$, Table 1). The changes in voltage dependence of the other CMTX mutations were also evident in the values of $V_{0}$ and $G_{\text {jmin }}$ (Table
1). The apparent increase of $V_{\mathrm{j}}$ dependence of mutant E102G was statistically significant $(p<0.02)$ for voltage steps greater than $\pm 70 \mathrm{mV}$. Further differences became apparent by analyzing the kinetics of $V_{\mathrm{j}}$-induced transitions of $G_{\mathrm{j}}$ (Fig. 5). The time course of current decay followed a single exponential relation (see traces in Fig. 4) and was symmetrical for positive and negative $V_{\mathrm{j}}>50$ $\mathrm{mV}$. Moreover, time constants were faster with increasing $V_{\mathrm{j}}$ for either Cx32wt or CMTX mutations (Fig. 5). The calculated values are comparable to those recently reported for mammalian Cx45 (Barrio et al., 1997). The voltage dependence of time constants for E102G was similar to that of Cx32wt (compare Fig. $5 A$ and $C$ ), whereas it was significantly faster $(p<0.05)$ for L56F at the higher transjunctional potentials (more than or equal to +60 and $-80 \mathrm{mV}$ ). Junctional currents evoked by Del111-116 (Fig. 5D) and R220stop (Fig. 5E) decayed with time constants that were up to fivefold faster than those calculated for Cx32wt at the same transjunctional potentials. These differences were statistically significant $(p<0.02)$, with the exception of the $+50 \mathrm{mV}$ pulse of R220stop. Thus, homotypic channels composed of L56F, E102G, Del111-116, and R220stop differ from Cx32wt in both the sensitivity and time course of their response to imposed $V_{\mathrm{j}}$ steps.

\section{Heterotypic channels between Cx32wt and CMTX mutations exhibit novel properties}

We have examined these functional differences further by investigating the ability of CMTX mutations to interact with $\mathrm{Cx} 32 \mathrm{wt}$ and the voltage sensitivity of the resulting heterotypic channels. All four functional mutations displayed the ability to interact with Cx32wt (Table 2). In the experiments analyzing voltage dependence, the cell expressing the CMTX mutation was held at a constant voltage, whereas the other one, expressing the wild-type protein, was depolarized or hyperpolarized. Thus, positive potentials denote that the right-hand cell, i.e., Cx32wt, was relatively positive, and, vice versa, negative potentials denote that the cell expressing a CMTX mutation is relatively positive (Fig. 6).

Heterotypic channels composed of L56F/Cx32wt (Fig. 6A,E), E102G/Cx32wt (Fig. 6B,F) or R220stop/Cx32wt (Fig. 6D,H) were characterized by a time-dependent channel closure over the duration of the voltage step, leading to a reduced steady-state conductance for transjunctional potentials of either polarity. Comparison of the experimentally obtained $G_{\mathrm{j}} / V_{\mathrm{j}}$ plots (Fig. $6 E-H$, solid lines) with the predicted equilibrium conductance, if the properties displayed in homotypic configurations had been maintained (Fig. 6E-H, dashed lines), revealed only a minor deviation in voltage sensitivity when L56F and E102G partnered $\mathrm{Cx} 32 \mathrm{wt}$. In general, there was a tendency for Cx32wt to increase and for CMTX mutations to decrease their voltage sensitivity in heterotypic configuration. These changes, which were more pronounced in the case of R220stop/Cx32wt (Fig. 6D,H), were quantitated by fitting the data to Boltzmann equations (see Table 1).

In contrast, heterotypic Del111-116/Cx32wt channels were markedly asymmetrical (Fig. 6C,G), showing rectification, i.e., decreased conductance for relatively positive and increased conductance for relatively negative potentials of the wild-type injected cell (Furshpan and Potter, 1959; Auerbach and Bennett, 1969; Jaslove and Brink, 1986; Giaume et al., 1987). On the one hand, depolarizing voltage steps to the cell expressing $\mathrm{Cx} 32 \mathrm{wt}$ evoked junctional currents that were closed by voltage with a faster time course and at a much lower threshold than that observed for the corresponding homotypic channels (compare 

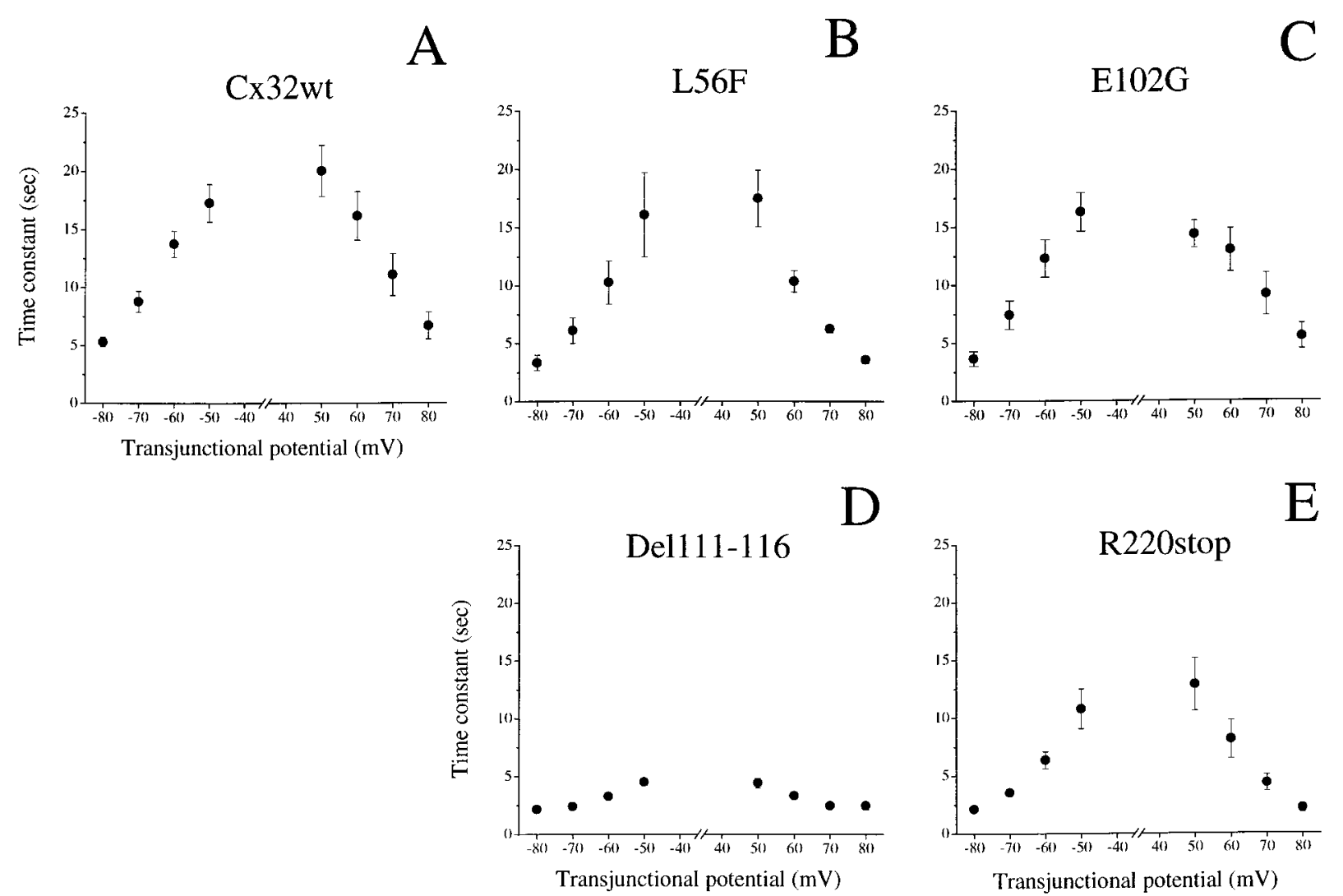

Figure 5. Time constants of voltage-dependent channel closure. For all experimental conditions, the time course of current decay followed a monoexponential relation (see traces in Fig. 4). Time constants $(\tau)$ were plotted versus positive and negative transjunctional potentials, corresponding to values that induced a consistent closure of channels composed of either Cx32wt or functional CMTX mutations. The values of $\tau$ were markedly faster for Del111-116 $(D)$ and R220stop $(E)$ than for Cx32wt $(A)$. Results are shown as the mean \pm SEM of the same number of pairs as indicated in Figure 4. When the error bars are not visible, SEM are within the size of the symbol.

Figs. $6 C, G$ and $4 A, F)$. On the other hand, depolarizing voltage steps applied to the Del111-116 injected cell resulted in steadystate currents that were not inhibited by transjunctional potentials up to $60 \mathrm{mV}$ and showed a slow voltage-dependent closure at the higher $V_{\mathrm{j}}$ (Fig. 6C,G). The dramatic deviation of Del111-116/ $\mathrm{Cx} 32 \mathrm{wt}$ heterotypic channels from the properties predicted on the basis of their behavior in homotypic oocyte pairs (Fig. 6G, dashed lines) was reflected in the Boltzmann parameters given in Table 1. This analysis reinforces the concept that novel gating properties result from the docking of connexons composed of distinct connexins.

\section{CMTX mutations retain the pattern of heterotypic compatibility of Cx32wt}

Because the formation of intercellular channels is a selective process that is also dependent on connexin compatibility (Bruzzone et al., 1993; Elfgang et al., 1995; White et al., 1995), we investigated the ability of the four functional CMTX mutations to interact with other connexins in heterotypic configurations. We paired oocytes expressing either one of the functional CMTX mutations with $\mathrm{Cx} 26, \mathrm{Cx} 46$, or $\mathrm{Cx} 50$, which have been shown to be compatible with Cx32wt (Barrio et al., 1991; White et al., 1995). Interestingly, $C x 26$ and $C x 46$ have an overlapping pattern of expression with Cx32 (Paul, 1986, 1995); more importantly, Cx32 and Cx46 are expressed in Schwann cells (Chandross et al., 1996a,b). Heterotypic oocyte pairs resulted in the development of robust junctional conductance, indicating that the CMTX mutations (L56F, E102G, Del111-116, and R220stop) are compatible with Cx26, Cx46, and Cx50 (Table 2). As expected, CMTX mutations failed to form channels with Cx40 (Table 2), indicating that they are restricted in their ability to interact functionally with other connexins and retain the same pattern of heterotypic compatibility as that of Cx32wt (Elfgang et al., 1995; White et al., 1995).

\section{CMTX mutations are $\mathrm{pH}-$ sensitive}

To study the susceptibility of the functional CMTX mutations to low pH-induced uncoupling (Turin and Warner, 1977), we have used a common acidification protocol that consisted of perfusing oocyte pairs with a $100 \%$ carbon dioxide-saturated medium (Werner et al., 1991; White et al., 1994; Wang et al., 1996). It has been shown recently that, under these experimental conditions, cytoplasmic $\mathrm{pH}$ decreases in oocytes within 5-7 min of exposure to $\mathrm{CO}_{2}$ from a level of 7.58 to 6.38 and does not decline further, even after prolonged perfusion with the same medium (Wang and Peracchia, 1997). Thus, we routinely have adopted a $10 \mathrm{~min}$ acidification protocol, followed by a recovery period, to compare the $\mathrm{pH}$ sensitivity of CMTX mutations under maximal uncoupling conditions. The values of junctional conductance were normalized to those recorded for 2-3 min before starting the perfusion with the $\mathrm{CO}_{2}$-equilibrated $\mathrm{MB}$ solution.

As previously reported (Swenson et al., 1989; Werner et al., 1991; Wang et al., 1996), homotypic channels composed of Cx32wt exhibited $\mathrm{pH}$ sensitivity (Fig. 7A). The time course showed an initial, transient increase, followed by a marked inhibition of junctional conductance, which decreased to $<20 \%$ of the 


\begin{tabular}{|c|c|c|}
\hline Oocyte injection (cell 1/cell 2) & $G_{\mathrm{j}}(\mu \mathrm{S})$ & Number of pairs \\
\hline Antisense/antisense & $0.04 \pm 0.03$ & 5 \\
\hline $\mathrm{L} 56 \mathrm{~F} / \mathrm{Cx} 32 \mathrm{wt}$ & $13.9 \pm 3.3$ & 9 \\
\hline E102G/Cx32wt & $20.5 \pm 6.4$ & 11 \\
\hline Del111-116/Cx32wt & $6.0 \pm 1.9$ & 10 \\
\hline R220stop/Cx32wt & $6.4 \pm 2.4$ & 7 \\
\hline $\mathrm{L} 56 \mathrm{~F} / \mathrm{Cx} 26$ & $9.3 \pm 2.5$ & 6 \\
\hline $\mathrm{L} 56 \mathrm{~F} / \mathrm{Cx} 46$ & $9.6 \pm 3.2$ & 4 \\
\hline $\mathrm{L} 56 \mathrm{~F} / \mathrm{C} \times 50$ & $10.3 \pm 3.2$ & 5 \\
\hline $\mathrm{E} 102 \mathrm{G} / \mathrm{Cx} 26$ & $5.0 \pm 0.9$ & 3 \\
\hline $\mathrm{E} 102 \mathrm{G} / \mathrm{Cx} 46$ & $5.7 \pm 1.4$ & 4 \\
\hline $\mathrm{E} 102 \mathrm{G} / \mathrm{Cx} 50$ & $3.6 \pm 1.3$ & 3 \\
\hline Del111-116/Cx26 & $5.9 \pm 0.8$ & 10 \\
\hline Del111-116/Cx46 & $4.8 \pm 1.1$ & 6 \\
\hline Del111-116/Cx50 & $5.9 \pm 1.0$ & 5 \\
\hline R220stop/Cx26 & $2.1 \pm 0.7$ & 5 \\
\hline R220stop/Cx46 & $3.4 \pm 0.9$ & 7 \\
\hline $\mathrm{R} 220$ stop/Cx50 & $2.0 \pm 0.6$ & 5 \\
\hline $\mathrm{L} 56 \mathrm{~F} / \mathrm{Cx} 40$ & $0.06 \pm 0.04$ & 4 \\
\hline $\mathrm{E} 102 \mathrm{G} / \mathrm{Cx} 40$ & $0.03 \pm 0.01$ & 6 \\
\hline Del111-116/Cx40 & $0.01 \pm 0.01$ & 4 \\
\hline R220stop/Cx40 & $0.01 \pm 0.01$ & 6 \\
\hline
\end{tabular}

Antisense-treated cells were injected with the specified cRNAs, and measurements of steady-state junctional conductance $\left(G_{\mathrm{j}}\right)$ were performed $24-48 \mathrm{hrs}$ after pairing, using a dual voltage-clamp procedure. Whereas the four functional CMTX mutations failed to interact with $\mathrm{Cx} 40$, homotypic $\mathrm{Cx} 40 / \mathrm{Cx} 40$ pairs injected with the same RNA batch developed a robust junctional conductance $(16.0 \pm 0.2 \mu \mathrm{S} ; n=3)$. Results are shown as the mean \pm SEM of the number of pairs indicated.

initial value at the end of the 10 min perfusion with $100 \% \mathrm{CO}_{2}$ gassed medium. The extent of uncoupling for human $\mathrm{Cx} 32 \mathrm{wt}$ was greater than that observed for the rat counterpart (cf. Swenson et al., 1989; Werner et al., 1991; Wang et al., 1996). The reduction in conductance was fully reversible on switching the perfusion medium to normal buffer. After a delay of $\sim 2$ min, conductance decreased at an average rate of $10.2 \% / \mathrm{min}$ and recovered at ate of $14.2 \% / \mathrm{min}$ (Fig. $7 A$ ). Oocytes expressing the mutations L56F (Fig. 7B) and R220stop (Fig. 7E) displayed an uncoupling behavior relatively similar to that of $\mathrm{Cx} 32 \mathrm{wt}$, with conductance decreasing at an average rate of 8.2 and $10.2 \%$ per minute, respectively, whereas the rates of recovery after maximal inhibition of junctional conductance were $14.8 \% / \mathrm{min}$ for $\mathrm{L} 56 \mathrm{~F}$ and $19.4 \% / \mathrm{min}$ for R220stop.

The time course of $\mathrm{pH}$-induced uncoupling of the two other functional mutations, E102G (Fig. 7C) and Del111-116 (Fig. 7D), was dramatically different from that of wild type. Plotting the mean decrease in junctional conductance of these mutations during perfusion with $100 \% \mathrm{CO}_{2}$ showed a fast drop that resulted in a complete uncoupling within 5 min of acidification. Whereas the average rate of uncoupling was 22.2 and $35.0 \%$ per minute for E102G and Del111-116, respectively (i.e., over twofold greater than for $\mathrm{Cx} 32 \mathrm{wt}$ ), the effect was reversible and junctional conductance recovered fully on cessation of perfusion with carbon dioxide-saturated buffer. Recovery occurred more promptly for E102G after the perfusion medium was switched to normal MB $(11.8 \% / \mathrm{min}$; Fig. $7 C)$, whereas there was a $6-7 \mathrm{~min}$ lag before the recoupling of oocyte pairs expressing Del111-116 started, at an average rate of $12.6 \% / \mathrm{min}$ (Fig. $7 D$ ).

\section{DISCUSSION}

The present study demonstrates that the naturally occurring CMTX mutations of Cx32 fall into two separate groups: those associated with a complete loss of function and those that retain the ability to form functional gap junction channels. Our findings confirm the previous observation that the R220stop mutation exhibits functional competence (Rabadan-Diehl et al., 1994; Omori et al., 1996; Wang and Peracchia, 1997) and extend it by establishing that the maintenance of channel-forming activity is shared by several CMTX mutations.

It has been reported that mice lacking Cx32 (Nelles et al., 1996) develop a late-onset peripheral neuropathy with similarities to that observed in CMTX patients (Anzini et al., 1997). These findings establish the causative role of $\mathrm{Cx} 32$ in the pathogenesis of CMTX and suggest that the loss of Cx32 channels in Schwann cells may be sufficient to induce the cellular abnormalities and demyelination that accompany this disease. The results of our functional analysis are compatible with those of $\mathrm{Cx} 32$ null mice, in that we find that a majority of mutations that have been tested have lost the ability to form channels. In addition, we have shown that the group of mutations retaining functional competence exhibits altered gating properties. Although changes in voltage sensitivity may not be relevant to the pathophysiology of CMTX, because Cx32 forms reflexive gap junctions in Schwann cells, our data raise the possibility that more subtle abnormalities of channel regulation eventually may lead to a functional deficit. This hypothesis is consistent with the independent observations of $\mathrm{Oh}$ and colleagues (1997), who recently have characterized two functional CMTX mutations with altered channel permeability.

\section{The effect of CMTX mutations on Cx32 function}

Structure-function studies of connexins have postulated that the major cytoplasmic domains, which are unique in sequence and length, are critical for the control of channel gating (Bruzzone et al., 1996; Yeager and Nicholson, 1996). In search of mutations retaining functional activity, we have chosen to study those identified by us (Ressot et al., 1996; Latour et al., 1997) and to focus on mutations occurring in the cytoplasmic portions.

Three of the functional mutations analyzed in this studyE102G, Del111-116, and R220stop-occur in these cytoplasmic regions. These mutations display increased sensitivity to transjunctional voltage and, in the case of Del111-116 and R220stop, faster time constants of channel closures. Differences in voltage dependence between Cx32wt and R220stop were not observed in a previous study (Rabadan-Diehl et al., 1994). It should be noted that, in the same study, Cx32wt channels were not gated by transjunctional voltage, an observation at variance with the findings of several other groups (Barrio et al., 1991; Suchyna et al., 1993; Bruzzone et al., 1994a; Bukauskas et al., 1995). It is difficult, therefore, to analyze the results of Rabadan-Diehl and colleagues (1994) in the context of voltage sensitivity.

The molecular determinants of voltage gating have not been elucidated completely, but it has been proposed that more than one region of the connexin molecule is involved in this process (Rubin et al., 1992; Verselis et al., 1994; White and Bruzzone, 1996). Our findings demonstrate that the amino acids deleted in the middle cytoplasmic loop and $\mathrm{C}$ terminus modulate the voltage-induced closure of $\mathrm{Cx} 32 \mathrm{wt}$ channels. A similar conclusion has been reached by swapping equivalent domains between connexins with different voltage sensitivity, because the degree of voltage dependence correlates with the identity of the middle cytoplasmic portion (Wang and Peracchia, 1996). Moreover, the 
A

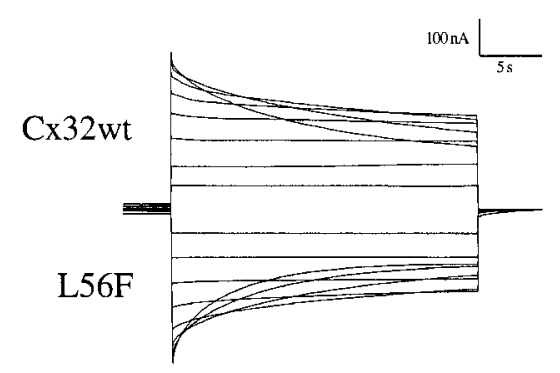

B

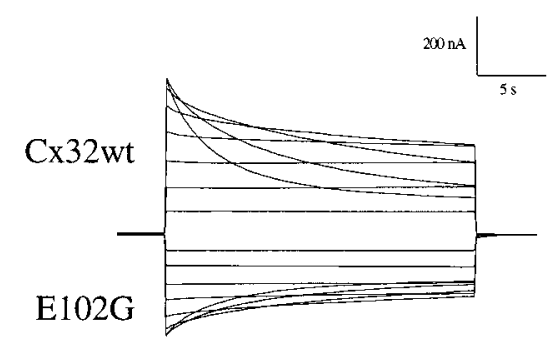

C

Del111-116

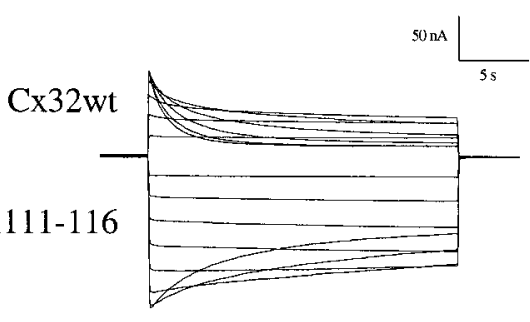

D

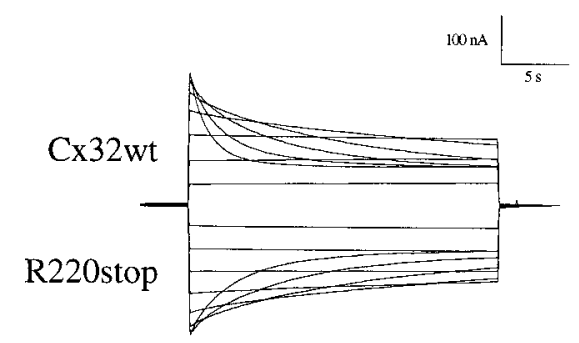

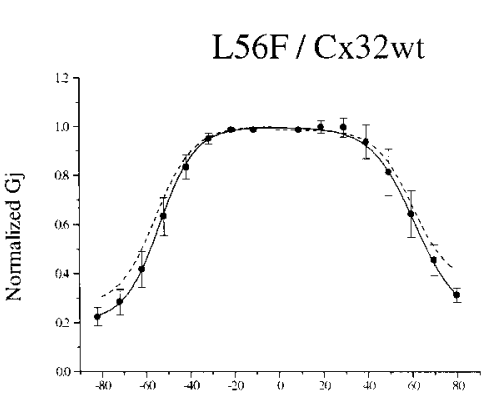

F
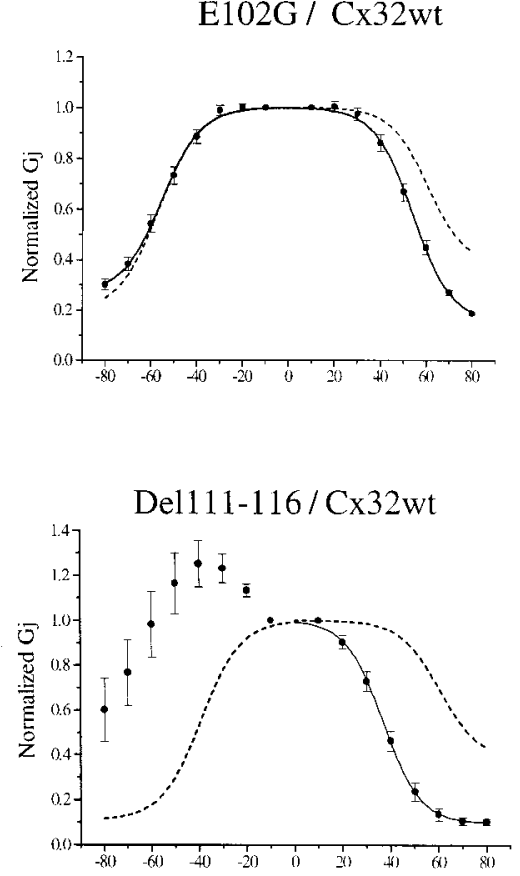

G

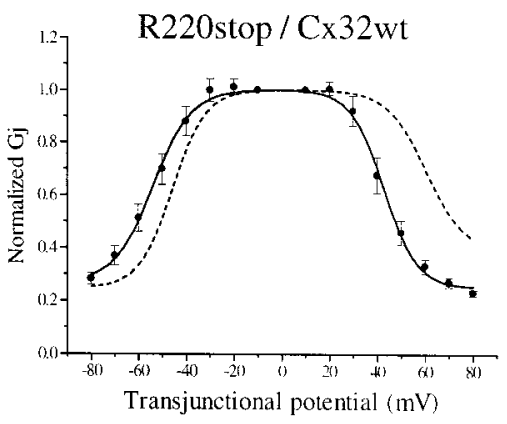

Figure 6. The formation of heterotypic channels between Cx32wt and CMTX mutations reveals unexpected electrical properties. Experimental conditions were as described in the legend to Figure 4. $A-D$, Time-dependent decay of junctional currents $\left(I_{\mathrm{j}}\right)$ induced by transjunctional voltage $\left(V_{\mathrm{j}}\right)$ steps applied in $10 \mathrm{mV}$ increments. When Cx32wt was paired to L56F $(A)$, E102G $(B)$, or R220stop $(D)$, currents exhibited a mainly symmetrical reduction for $V_{\mathrm{j}} \geq 30 \mathrm{mV}$. In contrast, Del111-116/Cx32wt heterotypic channels $(C)$ were characterized by a marked rectification and asymmetry of the voltage-gating behavior. $E-H$, Plots of mean steady-state conductance versus $V_{\mathrm{j}}$, normalized to the values obtained with a driving force of $\pm 10 \mathrm{mV}$. $V_{\mathrm{j}}$ is defined as positive for depolarization of the right-hand cell (e.g., Cx32wt) relative to the left-hand cell (e.g., either one of the CMTX mutations) and vice versa. Solid lines represent the best fits to Boltzmann equations for which the parameters are given in Table 1. Dashed lines represent the predicted conductance of heterotypic channels on the basis of the properties of homotypic channels. Results are shown as the mean \pm SEM of the following number of oocyte pairs: L56F/Cx32wt, $n=4$; E102G/Cx32wt, $n=5$; Del111-116/Cx32wt, $n=6$; R220stop/Cx32wt, $n=5$. 

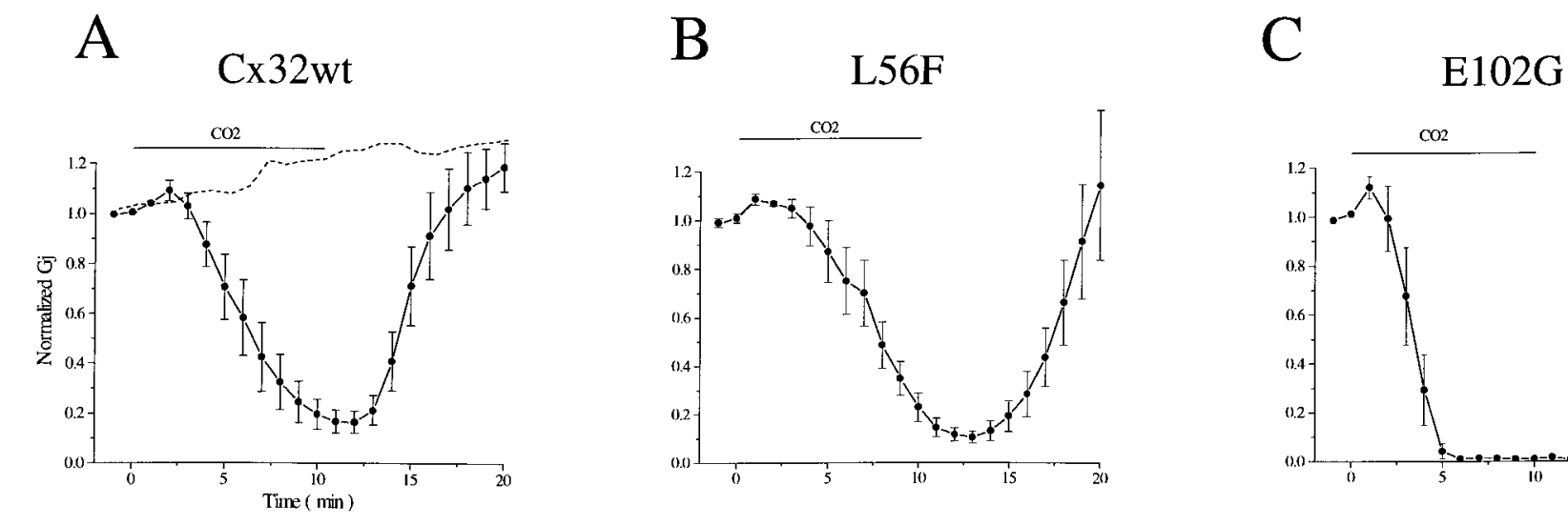

\section{$\mathrm{D}$}

\section{Del111-116}

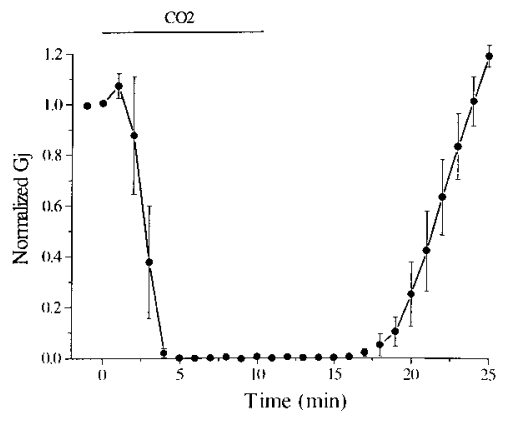

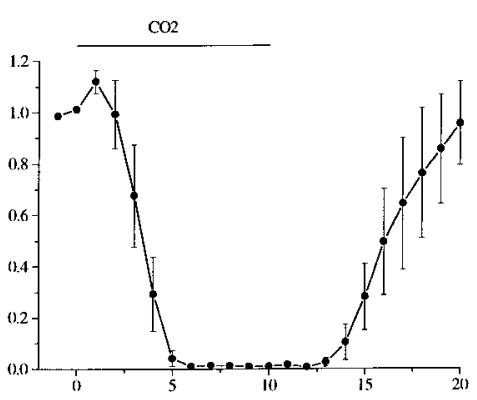

$\mathrm{E}$

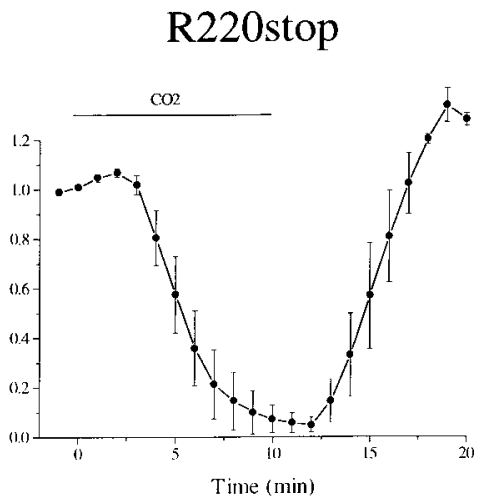

Figure 7. CMTX mutations in the middle cytoplasmic loop of $\mathrm{Cx} 32$ increase the sensitivity of intercellular channels to cytoplasmic acidification. Oocyte pairs were perfused with modified Barth's (MB) solution equilibrated with $100 \% \mathrm{CO}_{2}$ for 10 min (horizontal bar), after which the perfusion medium was returned to normal $\mathrm{MB}$ to allow the junctional conductance to recover. Junctional conductance was normalized to the average conductance values recorded for $3 \mathrm{~min}$ before the start of perfusion with $100 \% \mathrm{CO}_{2}$. In $A$, the dashed line represents the average values of junctional conductance measured between pairs expressing Cx32wt during perfusion with normal $\mathrm{MB}(n=3)$. In the case of E102G $(C ; n=5)$ and Del111-116 $(D ; n=4)$, both the rate and extent of $\mathrm{pH}$-dependent uncoupling were enhanced greatly. The $\mathrm{pH}$ sensitivity of $\mathrm{L} 56 \mathrm{~F}(B ; n=5)$ and $\mathrm{R} 220$ stop $(E ; n=5)$ was similar to that of $\mathrm{Cx} 32 \mathrm{wt}(A ; n=5)$. Results are shown as the mean \pm SEM of the specified number of pairs.

rectification induced by Del111-116, when paired heterotypically with Cx32wt, is also suggestive of specific changes of channel activity. It is known that connexins can modify their voltagegating properties when forming heterotypic channels (Barrio et al., 1991; Rubin et al., 1992; White and Bruzzone, 1996). Data obtained in the transfected cell expression system suggest that rectification can be explained by changes of single channel conductance (Bukauskas et al., 1995) that are the consequence of differences in the relative ionic permeability of the connexins forming the heterotypic channel (Cao et al., 1998). Thus, it is possible that the ionic preference of Del111-116 channels may differ from that of $\mathrm{Cx} 32 \mathrm{wt}$, although only studies of this mutation at the single channel level will resolve this issue.

The two functional mutations of the middle cytoplasmic loop, E102G and Del111-116, exhibited an increased sensitivity to intracellular acidification. These channels closed faster and, in contrast to those made of Cx32wt, completely. Recent work has demonstrated that the middle cytoplasmic loop (Wang and Peracchia, 1996; Wang et al., 1996) and the C-terminal portion (Morley et al., 1995; Ek-Vitorín et al., 1996; Wang and Peracchia, 1997) contain sequences that are critical for the $\mathrm{pH}$ sensitivity of
Cx32 and $\mathrm{Cx} 43$. The deletion of amino acids 111-116 results in a net loss of a positive charge (two histidines, positive, and one aspartic acid, negative, are lost), but a similar effect of $\mathrm{pH}$ is observed with the mutation E102G, which results in the loss of a single acidic residue. Although these experiments do not address the issue of interdomain interactions, they clearly reinforce the preeminence of the middle cytoplasmic loop in the sensitivity of channel gating to acidification.

The fourth functional mutant, L56F, is a missense mutation in the first extracellular loop. This mutation retained the same pattern of heterotypic compatibility as $\mathrm{Cx} 32 \mathrm{wt}$. Together with the observation that the CMTX mutations of the second extracellular loop that have been analyzed so far are loss-of-function (Bruzzone et al., 1994b; Deschênes et al., 1997; Yoshimura et al., 1998; this study), these data are consistent with the permissive role attributed to the first extracellular segment in the process of interconnexon pairing (White and Bruzzone, 1996). We have noticed, however, that increasing dilutions of the injected L56F resulted in a drastic loss of homotypic channel formation, whereas the same amounts of cRNA were able to interact efficiently with Cx32wt as well as with $\mathrm{Cx} 26, \mathrm{Cx} 46$, and $\mathrm{Cx} 50$, which are com- 
patible partners of Cx32 (Elfgang et al., 1995; White et al., 1995). Thus, a mutation in the first extracellular loop of $\mathrm{Cx} 32$ can influence interconnexon affinity.

\section{Cx32 mutations and the cellular mechanism of CMTX}

The functional consequences of $\mathrm{Cx} 32$ mutations seem to be of two kinds: those that result in loss of function and those that retain channel-forming ability. In the case of the nonfunctional group, we have reported previously that three such mutations were found predominantly at the cell surface of paired Xenopus oocytes (Bruzzone et al., 1994b). If these mutations also were targeted correctly to the incisures of Schmidt-Lanterman and paranodal loops of Schwann cells in vivo, they should be unable to dock and/or gate into the open configuration. Alternatively, the mutated Cx32 may be either rapidly degraded or intracellularly trapped. A defective connexin trafficking, leading to a conspicuous cytoplasmic accumulation, has been reported for several CMTX mutations transfected in mammalian cell lines (Omori et al., 1996; Deschênes et al., 1997). These disparities between Xenopus oocytes and mammalian cell lines, which regard only nonfunctional mutations, have been interpreted as the consequence of cell-type and species differences (Deschênes et al., 1997). The blockade of the radial pathway normally provided by Cx32 channels across the cytoplasm would, in turn, perturb the ability of Schwann cell to respond to axonal signals. In contrast, the group of functional mutations poses the challenge of understanding how the pathological changes characteristic of CMTX develop in vivo. Although these results have been obtained in an expression system that uses an amphibian cell, there has been a good agreement in the data derived from either Xenopus oocytes or mammalian cells with respect to connexin physiology (Elfgang et al., 1995; Veenstra et al., 1995; White et al., 1995; Cao et al., 1998). Moreover, three mutations, S26L, M34T, and R220stop, have been found to be functional in both the amphibian and mammalian expression systems (Rabadan-Diehl et al., 1994; Omori et al., 1996; Oh et al., 1997; this study). Thus, channelforming ability is an intrinsic property of several CMTX mutations. Alternatively, in the case of functional mutations, there could be additional changes in the noncoding region, as reported by Ionasescu and colleagues (1996), that inhibit gene transcription. We speculate, however, that some CMTX mutations retain functional competence in their natural cellular environment and that a more subtle abnormality is responsible for the development of the peripheral neuropathy.

Our initial characterization has revealed that functional mutations exhibit altered voltage dependence and $\mathrm{pH}$ gating. Other characteristics could be affected, because channels composed of different connexins are endowed with distinct properties with regard to unitary conductance, ionic permeability, and size selectivity (Steinberg et al., 1994; Elfgang et al., 1995; Koval et al., 1995; Veenstra, 1996; Cao et al., 1998). It has been reported recently that two CMTX mutations, S26L and M34T, produce functional channels with reduced permeability to molecules that can permeate Cx32wt channels (Oh et al., 1997). If similar alterations are shared by the group of functional mutations, the trafficking of cellular metabolites and signaling molecules would be perturbed, resulting in a functional deficit. It is conceivable that signals that originate from the axon fail to reach the nucleus of a myelinating Schwann cell, leading to the extinction of specific genes that control the expression of myelin proteins (Mirsky and Jessen, 1996; Scherer, 1997). The presence of a group of functional mutations should help in understanding the cellular basis of
CMTX disease by identifying the specific molecules that need to be exchanged via $\mathrm{Cx} 32$ channels but that are excluded from the mutated ones.

\section{REFERENCES}

Anzini P, Neuberg DH-H, Schachner M, Nelles E, Willecke K, Zielasek J, Toyka K, Suter U, Martini R (1997) Structural abnormalities and deficient maintenance of peripheral nerve myelin in mice lacking the gap junction protein connexin32. J Neurosci 17:4545-4551.

Auerbach AA, Bennett MVL (1969) A rectifying synapse in the central nervous system of a vertebrate. J Gen Physiol 53:211-237.

Ausubel FM, Brent R, Kingston RE, Moore DD, Seidman JG, Smith JA, Struhl K (1992) Short protocols in molecular biology. New York: Wiley.

Barrio LC, Suchyna T, Bargiello T, Xu LX, Roginski RS, Bennett MVL, Nicholson BJ (1991) Gap junctions formed by connexins 26 and 32 alone and in combination are differently affected by applied voltage. Proc Natl Acad Sci USA 88:8410-8414.

Barrio LC, Capel J, Jarillo JA, Castro C, Revilla A (1997) Speciesspecific voltage-gating properties of connexin 45 junctions expressed in Xenopus oocytes. Biophys J 73:757-769.

Bergoffen J, Scherer SS, Wang S, Oronzi Scott M, Bone LJ, Paul DL, Chen K, Lensch MW, Chance PF, Fischbeck KH (1993) Connexin mutations in X-linked Charcot-Marie-Tooth disease. Science 262:2039-2042.

Bone LJ, Dahl N, Lensch MW, Chance PF, Kelly T, LeGuern E, Magi S, Parry G, Shapiro H, Wang S, Fischbeck KH (1995) New connexin32 mutations in patients with X-linked Charcot-Marie-Tooth disease. Neurology 45:1863-1866.

Bone LJ, Deschênes SM, Balice-Gordon RJ, Fischbeck KH, Scherer SS (1997) Connexin32 and X-linked Charcot-Marie-Tooth disease. Neurobiol Dis 4:221-230.

Bruzzone R, Ressot C (1997) Connexins, gap junctions, and cell-cell signaling in the nervous system. Eur J Neurosci 9:1-6.

Bruzzone R, Haefliger J-A, Gimlich RL, Paul DL (1993) Connexin40, a component of gap junctions in vascular endothelium, is restricted in its ability to interact with other connexins. Mol Biol Cell 4:7-20.

Bruzzone R, White TW, Paul DL (1994a) Expression of chimeric connexins reveals new properties of the formation and gating behavior of gap junction channels. J Cell Sci 17:955-967.

Bruzzone R, White TW, Scherer SS, Fischbeck KH, Paul DL (1994b) Null mutations of connexin32 in patients with X-linked Charcot-Marie-Tooth disease. Neuron 13:1253-1260.

Bruzzone R, White TW, Paul DL (1996) Connections with connexins: the molecular basis of direct intercellular signaling. Eur J Biochem 238:1-27.

Bukauskas FF, Elfgang C, Willecke K, Weingart R (1995) Heterotypic gap junction channels (connexin26-connexin32) violate the paradigm of unitary conductance. Pflügers Arch 429:870-872.

Cao F, Eckert R, Elfgang C, Nitsche JM, Snyder SA, Hülser DF, Willecke K, Nicholson BJ (1998) A quantitative analysis of connexin-specific permeability differences of gap junctions expressed in HeLa transfectants and Xenopus oocytes. J Cell Sci 111:31-43.

Chandross KJ, Spray DC, Cohen RI, Kumar NM, Kremer M, Dermietzel $\mathrm{R}$, Kessler JA (1996a) TNF $\alpha$ inhibits Schwann cell proliferation, connexin46 expression, and gap junctional communication. Mol Cell Neurosci 7:479-500.

Chandross KJ, Kessler JA, Cohen RI, Simburger E, Spray DC, Bieri P, Dermietzel R (1996b) Altered connexin expression after peripheral nerve injury. Mol Cell Neurosci 7:501-518.

Cherryson AK, Yeung L, Dennerson ML, Nicholson GA (1994) Mutational studies in X-linked Charcot-Marie-Tooth disease (CMTX). Am J Hum Genet [Suppl] 55:1261A.

Dahl G (1992) The Xenopus oocyte cell-cell channel assay for functional analysis of gap junction proteins. In: Cell-cell interactions: a practical approach (Stevenson BR, Gallin WJ, Paul DL, eds), pp 143165. New York: Oxford UP.

Denoyelle F, Weil D, Maw MA, Wilcox SA, Lench NJ, Allen-Powell DR, Osborn AH, Dahl H-HM, Middleton A, Houseman MJ, Dodé C, Marlin S, Boulila-ElGaïed A, Ayadi H, Grati M, BenArab S, Bitoun P, Lina-Grande G, Godet J, Mustapha M, Loiselet J, El-Zir E, Aubois A, Joannard A, Levilliers J, Garabédian EN, Mueller RF, Gardner RJM, Petit C (1997) Prelingual deafness: high prevalence of a 30delG mutation in the connexin26 gene. Hum Mol Genet 6:2173-2177. 
Deschênes SM, Walcott JL, Wexler TL, Scherer SS, Fischbeck KH (1997) Altered trafficking of mutant connexin32. J Neurosci 17:9077-9084.

Ebihara L, Steiner E (1993) Properties of a non-junctional current expressed from a rat connexin 46 cDNA in Xenopus oocytes. J Gen Physiol 102:59-74.

Ek-Vitorín JF, Calero G, Morley GE, Coombs W, Taffet SM, Delmar M (1996) $\mathrm{pH}$ regulation of connexin43: molecular analysis of the gating particle. Biophys J 71:1273-1284.

Elfgang C, Eckert R, Lichtenberg-Fraté H, Butterweck A, Traub O, Klein RA, Hülser DF, Willecke K (1995) Specific permeability and selective formation of gap junction channels in connexin-transfected HeLa cells. J Cell Biol 129:805-817.

Fairweather N, Bell C, Cochrane S, Chelly J, Wang S, Mostacciuolo ML, Monaco AP, Haites NE (1994) Mutations in the connexin32 gene in X-linked dominant Charcot-Marie-Tooth disease (CMTX1). Hum Mol Genet 3:29-34.

Furshpan EJ, Potter DD (1959) Transmission at the giant motor synapses of the crayfish. J Physiol (Lond) 145:289-325.

Giaume C, Kado RT, Korn H (1987) Voltage-clamp analysis of a crayfish rectifying synapse. J Physiol (Lond) 386:91-112.

Goodenough DA, Paul DL, Jesaitis L (1988) Topological distribution of two connexin32 antigenic sites in intact and split rodent hepatocyte gap junctions. J Cell Biol 107:1817-1824.

Goodenough DA, Goliger JA, Paul DL (1996) Connexins, connexons, and intercellular communication. Annu Rev Biochem 65:475-502.

Gros DB, Jongsma HJ (1996) Connexins in mammalian heart function. BioEssays 18:719-730.

Harding AE (1995) From the syndrome of Charcot, Marie and Tooth to disorders of peripheral myelin proteins. Brain 118:809-818.

Ionasescu V, Searby C, Ionasescu R (1994) Point mutations of the connexin32 (GJB1) gene in X-linked dominant Charcot-Marie-Tooth neuropathy. Hum Mol Genet 3:355-358.

Ionasescu VV, Searby C, Ionasescu R, Neuhaus IM, Werner R (1996) Mutations of noncoding region of the connexin32 gene in X-linked dominant Charcot-Marie-Tooth neuropathy. Neurology 47:541-544.

Jaslove SW, Brink PR (1986) Mechanism of rectification at the electrotonic motor giant synapse of the crayfish. Nature 323:63-65.

Kelsell DP, Dunlop J, Stevens HP, Lench NJ, Liang JN, Parry G, Mueller RF, Leigh IM (1997) Connexin26 mutations in hereditary nonsyndromic sensorineural deafness. Nature 387:80-83.

Koval M, Geist ST, Westphale EM, Kemendy AE, Civitelli R, Beyer EC, Steinberg TH (1995) Transfected connexin45 alters gap junction permeability in cells expressing endogenous connexin43. J Cell Biol 130:987-995.

Krieg PA, Melton DA (1984) Functional messenger RNAs are produced by SP6 in vitro transcription of cloned cDNAs. Nucleic Acids Res 12:7057-7070.

Kumar NM, Gilula NB (1986) Cloning and characterization of human and rat liver cDNAs coding for a gap junction protein. J Cell Biol 103:767-776.

Kumar NM, Gilula NB (1996) The gap junction communication channel. Cell 84:381-388.

Latour P, Fabreguette A, Ressot C, Blanquet-Grossard F, Antoine JC, Calvas P, Chapon F, Corbillon E, Ollagnon E, Sturtz F, Boucherat M, Chazot G, Dautigny A, Pham-Dinh D, Vandenberghe A (1997) New mutations in the X-linked form of Charcot-Marie-Tooth disease. Eur Neurol 37:38-42.

Methfessel C, Witzemann V, Takahashi T, Mishina M, Numa S, Sakmann B (1986) Patch-clamp measurements on Xenopus laevis oocytes: currents through endogenous channels and implanted acetylcholine receptor and sodium channels. Pflügers Arch 407:577-588.

Mirsky R, Jessen KR (1996) Schwann cell development, differentiation, and myelination. Curr Opin Neurobiol 6:89-96.

Miyazaki T, Takeda Y, Murakami Y, Kawano H, Shimazu T, Toya S, Uyemura K (1995) Distribution of PASII/PMP22 and connexin32 proteins in the peripheral nervous system. Neurochem Int 27:377-383.

Morley GE, Taffet SM, Delmar M (1995) Intramolecular interactions mediate $\mathrm{pH}$ regulation of connexin43 channels. Biophys J 70:1294-1302.

Nelles E, Bützler C, Jung D, Temme A, Gabriel H-D, Dahl U, Traub O, Stümpel F, Jungermann K, Zielasek J, Toyka KV, Dermietzel R, Willecke K (1996) Defective propagation of signals generated by sympathetic nerve stimulation in the liver of connexin32-deficient mice. Proc Natl Acad Sci USA 93:9565-9570.
Oh S, Yi R, Bennett MVL, Trexler EB, Verselis VK, Bargiello TA (1997) Changes in permeability caused by connexin32 mutations underlie X-linked Charcot-Marie-Tooth disease. Neuron 19:927-938.

Omori Y, Mesnil M, Yamasaki H (1996) Connexin32 mutations from X-linked Charcot-Marie-Tooth disease patients: functional defects and dominant negative effects. Mol Biol Cell 7:907-916.

Paul DL (1986) Molecular cloning of cDNA for rat liver gap junction protein. J Cell Biol 103:123-134.

Paul DL (1995) New functions for gap junctions. Curr Opin Cell Biol 7:665-672.

Rabadan-Diehl C, Dahl G, Werner R (1994) A connexin32 mutation associated with Charcot-Marie-Tooth disease does not affect channel formation in oocytes. FEBS Lett 351:90-94.

Ressot C, Latour P, Blanquet-Grossard F, Sturtz F, Duthel S, Battin J, Corbillon E, Ollagnon E, Serville F, Vandenberghe A, Dautigny A, Pham-Dinh D (1996) X-linked dominant Charcot-Marie-Tooth neuropathy (CMTX): new mutations in the connexin32 gene. Hum Genet 98:172-175.

Rubin JB, Verselis VK, Bennett MVL, Bargiello TA (1992) Molecular analysis of voltage dependence of heterotypic gap junctions formed by connexins 26 and 32. Biophys J 62:183-195.

Satake M, Yoshimura T, Ohnishi A, Kobayashi T (1997) Connexin32 gene expression in rat sciatic nerves and cultured Schwann cells. Dev Neurosci 19:189-195.

Scherer SS (1997) Molecular genetics of demyelination: new wrinkles on an old membrane. Neuron 18:13-16.

Scherer SS, Deschênes SM, Xu Y-T, Grinspan JG, Fischbeck KH, Paul DL (1995) Connexin32 is a myelin-related protein in the PNS and CNS. J Neurosci 15:8281-8294.

Sosinsky GE (1996) Molecular organization of gap junction membrane channels. J Bioenerg Biomembr 28:297-309.

Spray DC, Dermietzel R (1995) X-linked dominant Charcot-MarieTooth disease and other potential gap-junction diseases of the nervous system. Trends Neurosci 18:256-262.

Spray DC, Harris AL, Bennett MVL (1981) Equilibrium properties of a voltage-dependent junctional conductance. J Gen Physiol 77:77-93.

Steinberg TH, Civitelli R, Geist ST, Robertson AJ, Hick E, Veenstra RD, Wang H-Z, Warlow PM, Westphale EM, Laing J, Beyer EC (1994) Connexin 43 and connexin 45 form gap junctions with different molecular permeabilities in osteoblastic cells. EMBO J 13:744-750.

Suchyna T, Xu LX, Gao F, Fourtner CR, Nicholson BJ (1993) Identification of a proline residue as a transduction element involved in the voltage gating of gap junctions. Nature 365:847-849.

Suter U, Snipes GJ (1995) Biology and genetics of hereditary motor and sensory neuropathies. Annu Rev Neurosci 18:45-75.

Swenson KI, Jordan JR, Beyer EC, Paul DL (1989) Formation of gap junctions by expression of connexins in Xenopus oocyte pairs. Cell 57:145-155.

Tan CC, Ainsworth PJ, Hahn AF, MacLeod PM (1996) Novel mutations in the connexin32 gene associated with X-linked Charcot-MarieTooth disease. Hum Mutat 7:167-171.

Turin L, Warner AE (1977) Carbon dioxide reversibly abolishes ionic communication between cells of early amphibian embryo. Nature 270:56-57.

Vance JM (1991) Hereditary motor and sensory neuropathies. J Med Genet 28:1-5.

Veenstra RD (1996) Size and selectivity of gap junction channels formed from different connexins. J Bioenerg Biomembr 28:327-337.

Veenstra RD, Wang H-Z, Beblo DA, Chilton MG, Harris AL, Beyer EC, Brink PR (1995) Selectivity of connexin-specific gap junctions does not correlate with channel conductance. Circ Res 77:1156-1165.

Verselis VK, Ginter CS, Bargiello TA (1994) Opposite voltage gating polarities of two closely related connexins. Nature 368:348-351.

Wang XG, Peracchia C (1996) Connexin32/38 chimeras suggest a role for the second half of inner loop in gap junction gating by low $\mathrm{pH}$. Am J Physiol 271:C1743-C1749.

Wang XG, Peracchia C (1997) Positive charges of the initial C-terminus domain of $\mathrm{Cx} 32$ inhibit gap junction gating sensitivity to $\mathrm{CO}_{2}$. Biophys J 73:798-806.

Wang XG, Li L, Peracchia LL, Peracchia C (1996) Chimeric evidence for a role of the connexin cytoplasmic loop in gap junction channel gating. Pflügers Arch 431:844-852. 
Werner R, Levine E, Rabadan-Diehl C, Dahl G (1989) Formation of hybrid cell-cell channels. Proc Natl Acad Sci USA 86:5380-5384.

Werner R, Levine E, Rabadan-Diehl C, Dahl G (1991) Gating properties of connexin32 cell-cell channels and their mutants expressed in Xenopus oocytes. Proc R Soc Lond [Biol] 243:5-11.

White TW, Bruzzone R (1996) Multiple connexin proteins in single intercellular channels: connexin compatibility and functional consequences. J Bioenerg Biomembr 28:339-350.

White TW, Bruzzone R, Wolfram S, Paul DL, Goodenough DA (1994) Selective interactions among the multiple connexin proteins expressed in the vertebrate lens: the second extracellular domain is a determinant of compatibility between connexins. J Cell Biol 125:879-892.

White TW, Paul DL, Goodenough DA, Bruzzone R (1995) Functional analysis of selective interactions among rodent connexins. Mol Biol Cell 6:459-470.

Wilders R, Jongsma HJ (1992) Limitations of the dual voltage-clamp method in assaying conductance and kinetics of gap junction channels. Biophys J 63:942-953.
Yamasaki H, Naus CCG (1996) Role of connexin genes in growth control. Carcinogenesis 17:1199-1213.

Yeager M, Nicholson BJ (1996) Structure of gap junction intercellular channels. Curr Opin Struct Biol 6:183-192.

Yoshimura T, Satake M, Ohnishi A, Tsutsumi Y, Fujikura Y (1998) Mutations of connexin32 in Charcot-Marie-Tooth disease type $\mathrm{X}$ interfere with cell-to-cell communication but not cell proliferation and myelin-specific gene expression. J Neurosci Res 51:154-161.

Zelante L, Gasparini P, Estivill X, Melchionda S, D'Agruma L, Govea N, Milá M, Della Monica M, Lutfi J, Shohat M, Mansfield E, Delgrosso K, Rappaport E, Surrey S, Fortina P (1997) Connexin26 mutations associated with the most common form of non-syndromic neurosensory autosomal recessive deafness (DFNB1) in Mediterraneans. Hum Mol Genet 6:1605-1609.

Zhou XW, Pfahnl A, Werner R, Hudder A, Llanes A, Luebke A, Dahl $\mathrm{G}$ (1997) Identification of a pore lining segment in gap junction hemichannels. Biophys J 72:1946-1953. 